\title{
Article
}

\section{Hex1, the Major Component of Woronin Bodies, is Required for Normal Development, Pathogenicity and Stress Response in the Plant Pathogenic Fungus Verticillium dahliae}

\author{
Vasileios Vangalis ${ }^{1}$, Ioannis A. Papaioannou², Emmanouil A. Markakis ${ }^{3}$, Michael \\ Knop ${ }^{2,4}$, Milton A. Typas ${ }^{1, *}$
}

1 Department of Genetics \& Biotechnology, Faculty of Biology, National and Kapodistrian University of Athens, Greece

2 Zentrum für Molekulare Biologie der Universität Heidelberg (ZMBH), DKFZ-ZMBH Alliance, Heidelberg, Germany

3 Laboratory of Mycology, Department of Viticulture, Vegetable Crops, Floriculture and Plant Protection, Institute of Olive Tree, Subtropical Crops and Viticulture, N.AG.RE.F., Hellenic Agricultural Organization - DEMETER, Heraklion, Crete, Greece

4 Cell Morphogenesis and Signal Transduction Group, DKFZ, DKFZ-ZMBH Alliance, Heidelberg, Germany

\section{* To whom correspondence should be addressed: matypas@biol.uoa.gr}

\begin{abstract}
Woronin bodies are membrane-bound organelles of filamentous ascomycetes that mediate hyphal compartmentalization by plugging septal pores upon hyphal damage. Their major component is the peroxisomal protein Hex1, which has also been implicated in additional cellular processes in fungi. Here, we analyzed the Hex1 homolog of Verticillium dahliae, an important asexual plant pathogen, and we report its pleiotropic involvement in fungal growth, physiology, stress response and pathogenicity. Alternative splicing of the Vdhex 1 gene can lead to the production of two Hex1 isoforms, which are structurally similar to their Neurospora crassa homolog. We show that $V d H e x 1$ is targeted to the septum, consistently with its demonstrated function in sealing hyphal compartments to prevent excessive cytoplasmic bleeding upon injury. Furthermore, our investigation provides direct evidence for significant contributions of Hex1 in growth and morphogenesis, as well as in asexual reproduction capacity. We discovered that Hex1 is required both for normal responses to osmotic stress and factors that affect the cell wall and plasma membrane integrity, and for normal resistance to oxidative stress and ROS homeostasis. The Vdhex1 mutant exhibited diminished ability to colonize and cause disease on eggplant. Overall, we show that Hex1 has fundamentally important multifaceted roles in the biology of $V$. dahliae.
\end{abstract}

Keywords: septal pore, hyphal integrity, virulence, ROS, heterokaryon incompatibility 


\section{Introduction}

The undifferentiated body (or thallus) of a typical filamentous fungus is the mycelium, a complex network of branched tubular cells called hyphae. In most fungi these are partitioned into distinct cellular compartments by internal cross-walls, the septae [1,2]. Hyphal compartments are continuous with one another due to the occurrence of septal pores, which allow the intercellular flow of cytoplasm, including organelles, ensure the rapid translocation of nutrients during colony establishment and facilitate the maintenance of cellular homeostasis during mycelial growth [3]. However, this ability of the mycelium to function as an integrated syncytium-like organism exposes it to a number of risks, e.g. excessive cytoplasmic leakage upon hyphal wounding or uncontrolled spread of selfish genetic elements (such as mycoviruses, transposable elements and senescence plasmids) following vegetative hyphal fusion. Therefore, the inter-compartmental traffic in hyphae must be highly regulated in order to protect the mycelium from such hazards, but also to permit cellular heterogeneity and differentiation during developmental processes [3-7].

Early studies in various ascomycetes implicated a specialized membrane-bound vesicle described as Woronin body (WB) in sealing of septal pores to prevent cytoplasmic loss in response to hyphal damage $[8,9]$. It was later shown that WBs are involved in the control of inter-cellular communication and the maintenance of hyphal heterogeneity [10]. Woronin bodies, which are exclusively found in Pezizomycotina [9], originate from peroxisomes and their biogenesis requires multiple peroxins [11]. They appear in electron microscopy images as electron-dense vesicles that are usually localized in close proximity to the septae, and they are rapidly tethered to the septal pore by interacting proteins following hyphal wounding $[12,13]$. At least 17 septal pore-associated WB-related proteins have been detected by mass spectrometry in Neurospora crassa [14].

The protein Hex1 was first characterized in $N$. crassa as the major component of WBs [15]. This protein spontaneously self-assembles into hexagonal crystals that comprise the dense core of WBs [16]. Conserved homologs of the hex1 gene have been identified and studied in several members of the Pezizomycotina [17-26]. The gene presumably resulted from duplication of the ancestral gene encoding the eukaryotic initiation factor 5A (elF-5A) [16]. After this duplication, hex 1 followed a different evolutionary trajectory that led to a new function by acquiring those amino acids that are responsible for its peroxisomal targeting and self-assembly. Hex 1 genes retain a conserved intron close to their $\mathrm{N}$-terminus, and alternative splicing of this intron has been shown to produce two isoforms of the protein [17-19].

Deletion of hex 1 in several fungi generally led to excessive hyphal bleeding after wounding [20,27], but also had pleiotropic effects on additional phenotypes associated with vegetative growth, asexual reproduction and stress response against osmotic and cell wall-perturbating agents [24-26]. Regarding pathogenicity and virulence, conflicting results have been gathered from studies on plant, insect and human pathogens. These range from important roles of Hex1 in the formation of 
appressoria (infection structures) and pathogenicity in Magnaporthe grisea [18] to moderately reduced or delayed virulence in Fusarium graminearum [22], Aspergillus flavus [25] and $A$. fumigates [13], and no significant defects in pathogenicity of Colletotrichum orbiculare [23] and Metarhizium robertsii [26].

The ascomycete Verticillium dahliae causes a wilt disease on a wide range of commercially important plants and crops, and it is responsible for enormous annual economic losses worldwide [28]. Its resting structures (microsclerotia), which can remain viable in the soil for several years, germinate upon induction by exudates from adjacent plant roots to form hyphae. This is followed by root penetration and colonization, leading the fungus to the host vascular system, through which it can cause systemic infection of the plant [29]. Except for the apical cells of its mycelium, hyphal compartments of $V$. dahliae are regularly septated, and upon hyphal injury WBs rapidly plug the pores of the flanking septae to seal damaged compartments $[30,31]$. This fungus is thought to completely lack a sexual stage and thus propagates exclusively through the dispersion of its asexual spores (conidia). A parasexual cycle, initiated by hyphal fusion between individuals with different genotypes to the formation of heterokaryons, has been described in Verticillium and thought to increase genetic diversity through random chromosome assortment and frequent mitotic recombination [28,32]. Nevertheless, heterokaryon formation is restricted by incompatibility barriers [28,31], which seal and destroy incompatible fused cells, while the remaining mycelium remains unaffected $[7,33]$.

This study aimed at the identification and functional characterization of hex1 in fundamental biological processes of the important plant pathogen $V$. dahliae. For this, we deleted its hex1 homolog to address the involvement of the gene in hyphal integrity, growth and development, pathogenicity, response to osmotic, cell wallperturbating and oxidative stress, and heterokaryon incompatibility. Our investigations revealed important roles of Hex1 in the biology of $V$. dahliae. 


\section{Materials and Methods}

\subsection{Fungal Strains, Culture Conditions and Fungal DNA Isolation and Manipulation}

All fungal strains that were constructed and used in this study are listed in Table S1. Preparation and maintenance of monoconidial strains, culture media and conditions have been previously described [34].

Total genomic DNA of fungal strains was extracted according to published methods [34]. Standard and previously described procedures were followed for PCR amplification (all oligos are listed in Table S2), cloning and maintenance of plasmids in E. coli strain DH5a (a list of plasmids is provided in Table S3), restriction digestion and Sanger sequencing [34,35].

\subsection{Agrobacterium tumefaciens-Mediated Transformation of V. dahliae}

The hypervirulent $A$. tumefaciens strain AGL-1 was transformed with binary plasmid vectors using a $\mathrm{CaCl}_{2} /$ heat shock-mediated freeze-thaw method [36]. The resulting $A$. tumefaciens strains were used for transforming $V$. dahliae with protocols modified from [37]. After growth of $A$. tumefaciens in MM supplemented with the proper selective antibiotics for $48 \mathrm{~h}\left(28^{\circ} \mathrm{C}, 180 \mathrm{rpm}\right)$, the culture was diluted to $\mathrm{OD}_{600}=0.1$ and incubated for $6 \mathrm{~h}$ in acetosyringone-containing induction medium (IM; $25^{\circ} \mathrm{C}, 180 \mathrm{rpm}$, without antibiotics). Aliquots of this culture $(100 \mu \mathrm{L})$ were then mixed with $100-\mu \mathrm{L}$ aliquots of a conidial suspension of the desired $V$. dahliae strain $\left(10^{7}\right.$ conidia/mL, prepared from 7-day-old cultures) and plated on sterile cellophane sheets on IM agar. The mixture was incubated for $48 \mathrm{~h}$ at $25^{\circ} \mathrm{C}$ before its transfer to selective medium (PDA amended with $200 \mu \mathrm{g} / \mathrm{mL}$ cefotaxime, $50 \mu \mathrm{g} / \mathrm{mL} 5$ fluorouracil and $100 \mu \mathrm{g} / \mathrm{mL}$ geneticin and/or $15 \mu \mathrm{g} / \mathrm{mL}$ hygromycin $\mathrm{B}$ ).

\subsection{Protoplast Transformation of V. dahliae}

At least $10^{8}$ conidia of the desired $V$. dahliae strain were incubated in $\mathrm{CM}$ for 16 $\mathrm{h}\left(25^{\circ} \mathrm{C}, 175 \mathrm{rpm}\right)$. Conidia/germlings were then pelleted, resuspended into a phosphate- $\mathrm{KCl}$ buffer $\left(0.6 \mathrm{M} \mathrm{KCl}, 1 / 15 \mathrm{M} \mathrm{KH}_{2} \mathrm{PO}_{4}\right.$ and 1/15 $\mathrm{M} \mathrm{Na}_{2} \mathrm{HPO}_{4}, \mathrm{pH}$ 5.8; supplemented with $25 \mathrm{mM}$ DTT) and incubated for $2 \mathrm{~h}$ at $30{ }^{\circ} \mathrm{C}$ (50 rpm). Protoplastation was performed by transferring the treated germlings to fresh phosphate- $\mathrm{KCl}$ buffer supplemented with $8 \mathrm{mg} / \mathrm{mL}$ of a lysing enzyme mix from Trichoderma harzianum (Sigma-Aldrich) and further incubating the mix at $30{ }^{\circ} \mathrm{C}(50$ rpm) for 1-3 h. Protoplasts were separated from aggregated cellular debris by filtering through four layers of sterile gauge and resuspended into STC solution (1.2 M sorbitol, $10 \mathrm{mM}$ Tris-Cl pH 7.5 and $50 \mathrm{mM} \mathrm{CaCl}_{2}$ ) at a final concentration of $10^{8} / \mathrm{mL}$. Aliquots $(100 \mu \mathrm{L})$ of this protoplast suspension were mixed with 2-8 $\mu \mathrm{g}$ of DNA and incubated for $30 \mathrm{~min}$ on ice before the addition of $200 \mu \mathrm{L}$ of PTC buffer (40\% PEG$6000,25 \mathrm{mM}$ Tris- $\mathrm{Cl} \mathrm{pH} 7.5$ and $25 \mathrm{mM} \mathrm{CaCl}_{2}$ ) and further incubation for $20 \mathrm{~min}$ on 
ice. This was followed by the stepwise addition of $1 \mathrm{~mL}$ of fresh PTC buffer and incubation for 15 min on ice. The mixture was then washed 3 times with STC buffer, resuspended into fresh STC buffer and plated on regeneration agar medium $(20.54 \mathrm{~g}$ sucrose, $0.1 \mathrm{~g}$ yeast extract and $0.14 \mathrm{~g}$ casamino acids per $100 \mathrm{~mL}$ ), overlaid with a sterile cellophane sheet. Following incubation at $25^{\circ} \mathrm{C}$ for $24 \mathrm{~h}$, the cellophane sheet was transferred onto the appropriate selective medium (PDA amended with 100 $\mu \mathrm{g} / \mathrm{mL}$ geneticin and/or $15 \mu \mathrm{g} / \mathrm{mL}$ hygromycin B).

\subsection{Deletion, Complementation and sGFP-tagging of V. dahliae hex1}

The NEBuilder HiFi DNA Assembly Master Mix (New England Biolabs) was used (according to the manufacturer's recommendations) for the construction, in 2 steps, of a plasmid vector for hex 1 deletion by homologous recombination. The first reaction resulted in a plasmid containing 2,000 bp-long homologous arms (amplified from the genomic DNA of $V$. dahliae isolate Ls.17 using the Herculase II Fusion DNA polymerase; Agilent) flanking the neo cassette (conferring resistance to geneticin) from plasmid pSD1, in the backbone of plasmid pOSCAR. A second NEBuilder HiFi DNA Assembly reaction was then used for the addition to the construct of the hsv-tk thymidine kinase gene (from plasmid pGKO2) for selection against ectopic transformants. This recombinant plasmid vector (pOSCAR-hex-KO) was used for transformation of $V$. dahliae, using the Agrobacterium tumefaciens strain AGL-1. Monoconidial cultures were prepared from resistant $V$. dahliae colonies, validated as hex 1 deletion mutants by spore PCR and Southern blot analysis (DIG DNA Labeling and Detection Kit, Sigma-Aldrich), and stored as $25 \%$ glycerol stocks at $-80{ }^{\circ} \mathrm{C}$.

The full-length coding sequence of hex1 plus 2,000 bp-long flanks were amplified from the genomic DNA of $V$. dahliae Ls.17 (using the KAPA HiFi DNA polymerase, Roche) for complementing hex1 deletion strains. The resulting $4.8 \mathrm{~kb}-$ long amplicon was co-transformed into $V$. dahliae protoplasts with plasmid pUCATPH, which contains the hph cassette (conferring resistance to hygromycin B). Monoconidial transformants were confirmed by spore PCR and stored at $-80^{\circ} \mathrm{C}$.

We performed C-terminal sGFP-tagging of hex 1 by using the NEBuilder $\mathrm{HiFi}$ DNA Assembly kit to generate a construct consisting of the full-length hex1 ORF together with its 2,000 bp-long upstream flank (which presumably includes its endogenous promoter) fused to the SGFP coding sequence from plasmid pIGPAPA, the terminal region of $A$. nidulans tef1 and the $h p h$ selection cassette from plasmid pFC332. The Herculase II Fusion DNA Polymerase was used for the amplification of all fragments, which were then assembled into a new recombinant plasmid (pOSCAR-hex-GFP) in the backbone of pOSCAR by a NEBuilder reaction. This was then transformed into $V$. dahliae $\Delta$ hex 1 mutants using the $A$. tumefaciens strain AGL1. Resistant fungal colonies were single-cell purified, microscopically checked and stored at $-80^{\circ} \mathrm{C}$. 


\subsection{Cytoplasmic and Nuclear Fluorescent Labeling of V. dahliae}

The sGFP gene was used for fluorescent labeling of either the cytoplasm or histone $\mathrm{H} 1$ (as a nuclear label) of $V$. dahliae strains. Construction of strains with cytoplasmic sGFP expression was performed by cloning the sGFP expression cassette from plasmid pIGPAPA and the neo cassette from plasmid pSD1 to the polylinker of plasmid pBluescript II (using the T4 DNA ligase, Takara Bio). The resulting plasmid pBS-GFP-gen was used to transform $V$. dahliae protoplasts, and monoconidial transformants were checked microscopically for robust cytoplasmic sGFP expression.

Plasmid pMF357, which carries the hph cassette and a fusion construct of the sGFP gene to the $N$. crassa histone $\mathrm{H} 1$ gene, was used to transform $V$. dahliae protoplasts for nuclear labeling. Monoconidial transformants were checked microscopically for green nuclear fluorescence.

\subsection{Morphological and Physiological Characterization of V. dahliae Strains}

Previously described methods [34] were used for the morphological and physiological characterization of wild-type and mutant $V$. dahliae strains, with minor modifications. Colony diameters were measured for the determination of growth rates every 5 days during growth on $\mathrm{CM}$, at $25^{\circ} \mathrm{C}$. Mycelial plugs $(1.0 \mathrm{~cm}$ in diameter) from the colony periphery of 20-day-old cultures were transferred into $500 \mu \mathrm{L}$ of sterile water and vortexed extensively before determining conidial concentrations using a Neubauer improved cell counting chamber. Frequency of germination was determined by inoculating $1.0 \times 10^{6}$ conidia of each strain into $\mathrm{CM}$ and checking microscopically for germling formation after 14 hours of growth at $25{ }^{\circ} \mathrm{C}$. All experiments were performed in triplicate.

\subsection{Plant Pathogenicity Assays}

Preparation of eggplant seedlings and conidial suspensions from $V$. dahliae cultures for their pathogenicity assessment was performed as previously described [38], with minor modifications. Seedlings were transplanted at the one true-leaf stage in $100-\mathrm{mL}$ pots containing soil substrate, before drenching with $20 \mathrm{~mL}$ of conidial suspension $\left(5.0 \times 10^{6}\right.$ conidia/mL) or sterile water (control plants) per pot. Plants were maintained under controlled conditions at $23 \pm 3{ }^{\circ} \mathrm{C}$ with a 12-h light-dark cycle.

Typical wilt symptoms were recorded every 3-4 days for 29 days postinoculation (d.p.i.) for monitoring disease progress over time, and on the 45th d.p.i. for the determination of final disease severity. Disease parameters were recorded according to previously described criteria $[38,39]$. Disease severity at each time point was defined as the percentage of symptomatic leaves, and results were plotted over time to generate disease progress curves. These were used for the determination of 
relative AUDPC (area under disease progress curve) values [38]. In addition, plant growth parameters were recorded at 29 d.p.i. [39].

The presence of the applied $V$. dahliae strain in plant tissues was assessed by fungal re-isolation to verify systemic infection at 29 d.p.i., according to [38]. In particular, 9 plant stems per treatment were randomly selected and 3 xylem chips from different sites along the stem (base, middle and upper part) were transferred onto acidified PDA medium after the removal of the phloem. The pathogen isolation ratio was expressed as the percentage of positive xylem chips of each plant.

\subsection{Stress Response Assays and ROS Detection}

Two methods were used to analyze the sensitivity of $V$. dahliae wild-type and mutant strains to varying concentrations of a number of stress-inducing factors and chemicals that are commercially used as fungicides. In summary, we tested growth responses to factors that induce osmotic stress: $\mathrm{NaCl}$, sorbitol; oxidative stress: $\mathrm{H}_{2} \mathrm{O}_{2}$, paraquat, $\mathrm{N}$-acetyl cysteine, iprodione; cell wall/plasma membrane damage or perturbation: calcofluor white M2R, Congo red, SDS, amphotericin B (Biosera), fluconazole (Pfizer), farnesol; and other fungicides that inhibit sporulation and germination: cymoxanil, fosetyl-Al (Bayer), mandipropamid, cyflufenamid (chemicals were purchased from Sigma-Aldrich, unless otherwise specified, and fresh solutions were prepared in water directly before each experiment). The first method was a spot dilution assay, in which $10 \mu \mathrm{L}$ of 10 -fold serial dilutions of conidial suspensions (5.0 $\times$ $10^{6}$ to $5.0 \times 10^{3}$ conidia $/ \mathrm{mL}$ ) were spotted on $\mathrm{CM}$ agar plates containing the desired stress factor and incubated at $25{ }^{\circ} \mathrm{C}$ for 3 days. In addition, for each stress condition/concentration, relative growth inhibition was determined according to the formula: \% growth inhibition $=[$ (colony diameter on CM - colony diameter in stress condition) / (colony diameter on $\mathrm{CM})] \times 100$. Each experiment was performed in triplicate.

The generation/accumulation of superoxide anion radicals $\left(\mathrm{O}_{2}{ }^{-}\right)$in the mycelium of $V$. dahliae strains was also examined in response to stress-inducing compounds. For this, the nitro blue tetrazolium chloride (NBT; Cayman Chemical) staining method was used: fungal colonies were grown on $\mathrm{CM}$ plates supplemented with the desired stress factor for 20 days before the addition of $10 \mathrm{~mL}$ of a $0.2 \%$ NBT solution on each plate. Following incubation at $25^{\circ} \mathrm{C}$ (in the dark) for $45 \mathrm{~min}$, the solution was discarded, plates were washed with ethanol, incubated again for $45 \mathrm{~min}$ in the dark, and briefly air-dried before recording the assessment of the staining result. All staining assays were performed in triplicate.

\subsection{Generation of nit Mutants and Heterokaryon Compatibility Tests}

Nitrate non-utilizing (nit) mutants of the $V$. dahliae $\Delta$ hex1 strain were generated by the ultraviolet irradiation method and selection on the chlorate-containing medium WAC that have been previously described [40]. Phenotypic classification of nit 
mutants and complementation tests in 96-well plates were also performed according to our previously described procedures [40]. Each pairing was performed in 3 independent repetitions.

\subsection{Microscopy}

Fungal conidia, germlings and hyphae were imaged using a Zeiss Axioplan epifluorescence microscope equipped with a differential interference contrast (DIC) optical system, a set of filters G $365 \mathrm{~nm}$ (excitation) and LP $420 \mathrm{~nm}$ (emission), and a Zeiss Axiocam MRc5 digital camera. Calcofluor white M2R (Sigma-Aldrich) was used for cell wall staining by its addition to the samples (to a final concentration of 10 $\mu \mathrm{g} / \mathrm{mL}$ ) and inbucation at room temperature for $5 \mathrm{~min}$ before imaging. Methylene blue staining (final concentration $0.005 \% \mathrm{w} / \mathrm{v}$ ) was used to differentiate live from dead cells. The samples were incubated at $25^{\circ} \mathrm{C}$ for $5 \mathrm{~min}$, in the dark, before imaging.

Time-lapse microscopy was performed using a Nikon Ti-E epifluorescence microscope equipped with an autofocus system (Perfect Focus System, Nikon), a LED light engine (SpectraX, Lumencor), filter sets $390 / 18$ and $435 / 48$ or $469 / 35$ and 525/50 (excitation and emission filter, respectively; all from Semrock except for 525/50, which was from Chroma), and a sCMOS camera (Flash4, Hamamatsu). Images were acquired every $10 \mathrm{~min}$ for $24 \mathrm{~h}$ (with exposure of 50 and $20 \mathrm{~ms}$ for the green and blue channel, respectively), and later processed using ImageJ [41]. Images were adjusted to uniform contrast across all time points, pixel intensity plots were generated using the plot profile (for septae) and surface plot (for the whole area) functions of ImageJ, and background subtraction was performed with a rolling ball radius of 50.0 pixels and default parameters.

\subsection{Bioinformatic Analyses and Statistics}

Homology searches for the identification of Hex1 orthologs in V. dahliae and other fungal species were performed using Blast $N$, tBlast $N$ and BlastP searches (NCBI; https://blast.ncbi.nlm.nih.gov/Blast.cgi). All protein sequences were retrieved from GenBank (NCBI; https://www.ncbi.nlm.nih.gov/genbank) and aligned using the MUSCLE and ClustalW algorithms implemented in MEGA $X$ [42]. Reads from previously published RNA-seq experiments of $V$. dahliae were obtained from the Sequence Read Archive (NCBI SRA; https://www.ncbi.nlm.nih.gov/sra; datasets with accession numbers SRP020910, SRP013922, SRP041118, SRP119401, SRP198907, SRP183605, SRP244752, ERP123035 and ERP002524) using BLAST analyses and aligned to the hex 1 coding sequences that flank the predicted intron, using MEGA $X$.

The Maximum Likelihood (ML) method, implemented in the MEGA $X$ software suite, was used for the generation of the phylogenetic tree of Hex1 sequences. Sequence alignment was performed using the MUSCLE algorithm, and then it was manually corrected. The Le Gascuel (LG) model, using a discrete Gamma 
distribution (parameter $=0.4452$ ) with 5 rate categories, exhibited the lowest Bayesian Information Criterion (BIC) and corrected Akaike Information Criterion (AICc) values and was therefore chosen as the best-fit substitution model for the construction of the tree. The Neighbor-Join and BioNJ algorithms were applied to generate the initial tree for the heuristic $\mathrm{ML}$ search, and the partial deletion option was used for handling alignment gaps. Bootstrap analysis with 1,000 replications was performed for assessing tree confidence.

Prediction of the Hex1 secondary structure was performed using the PSIPRED Workbench (UCL-CS Bioinformatics) [43]. For homology modeling of the Hex1 protein, the HMM-based tool HHPred [44] and MODELLER 9.25 [45] were used, based on the highly similar crystal structure of Hex1 from $N$. crassa (PDB $1 \mathrm{KHI}$ ) (probability: $99.93 \%$, E-value: $1.9 \times 10^{-23}$ ). Protein structures were visualized and compared using PyMOL 2.4 (https://pymol.org/2).

Statistical significance of differences between compared datasets was assessed using the analysis of variance (ANOVA) test, following the evaluation of homogeneity of variance across samples ( $F$-test $p \leq 0.05$ ). Datasets were then subjected to means separation using the Tukey's honestly significant difference (HSD) test. 


\section{Results}

\subsection{Identification and Characterization of the VdHex1 Homolog}

To identify homologs of Hex1 in $V$. dahliae, the 176 aa protein sequence of $N$. crassa (GenBank AAB61278) was used as query in a tBlastN search of the $V$. dahliae genome (strain Ls.17). This yielded a single highly similar sequence of 197 aa (similarity: $80.0 \%$, E-value: $5.0 \times 10^{-91}$ ), encoded by the 786 bp-long gene VDAG_01749. Sequence alignment revealed that this protein was missing the $\mathrm{N}$ terminal hexapeptide MGYYDD, which is however highly conserved across Hex1 homologs of various ascomycetes. Further investigation of the gene model VDAG_01749 suggested the presence of a putative intron close to the start codon of the gene that could have been erroneously predicted and led to the description of a truncated ORF. The existence of this intron is conserved among various fungi [1719]. To validate our hypothesis, we retrieved 120 reads from previously generated RNA-seq datasets by BLAST searches against the hex-1 N-terminal region, and we mapped them on its genomic sequence (Figure 1A). More than half of them (67 reads) were mapped on both flanks of our predicted intron, with an internal gap of $217 \mathrm{bp}$, which corresponds to a genomic sequence with GT-AG boundaries. These findings are consistent with splicing of an intron at these positions, yielding a protein of 188 aa and molecular weight of $21 \mathrm{kDa}$. Twenty reads exhibited a different mapping pattern that suggests alternative splicing of the intron by using an internal AG donor site (Figure $1 \mathrm{~A}$ ), to produce a larger but highly similar isoform of the Hex1 protein (209 aa, $23.5 \mathrm{kDa}$ ). This has also been observed in a number of fungi [18,21]. Finally, 33 reads showed gapless alignments on the genomic sequence of hex1, suggesting the presence of pre-mRNAs in the RNA-seq data. Both $V$. dahliae isoforms of Hex1 possess the typical N-terminal hexapeptide MGYYDD and the characteristic peroxisome-targeting signal (SRL tripeptide; PTS1 [16]) at their Cterminus (Figure S1).

Multiple sequence alignment with Hex1 homologs of selected representative species revealed that, apart from the initial hexapeptide, the $\mathrm{N}$-terminal region is highly variable across fungi (Figure S1). In V. dahliae and also some other species, this region of the protein lacks the polyhistidine motif that has been shown to be involved in Hex1 targeting to the septal wall in Aspergillus fumigatus [13]. This suggests that different species have presumably adopted different mechanisms for recruiting WBs to the septum. The remaining part of the protein up to its C-terminus (which constitutes about $78 \%$ of the total protein length) is highly conserved even between species of different orders. Secondary structure prediction revealed that $V$. dahliae Hex1 contains all characteristic motifs, including the 11 beta-sheets and 2 helices, as well as the conserved histidine residue (at position 51) which has been implicated in crystal formation in N. crassa [16] (Figure S1). Furthermore, homology modeling of $V$. dahliae Hex1 demonstrated that the protein is expected to have essentially the same tertiary structure as the solved structure of its $N$. crassa 
homolog (PDB 1KHI [16]), notably with two perpendicular antiparallel $\beta$-barrels, except for the variable $\mathrm{N}$-terminal region, which is probably in a disordered state (Figure 1B).

Genomic searches revealed that all known Verticillium species possess a single Hex1 homolog, with the exception of $V$. longisporum, a nearly diploid hybrid [46], which has two non-identical paralogs. Phylogenetic analysis of the Hex1 homologs of Verticillium and members of several Pezizomycotina orders of varying phylogenetic distances demonstrated that the evolution of this single-copy gene generally follows the divergence pattern of the species (Figure 1C).

A

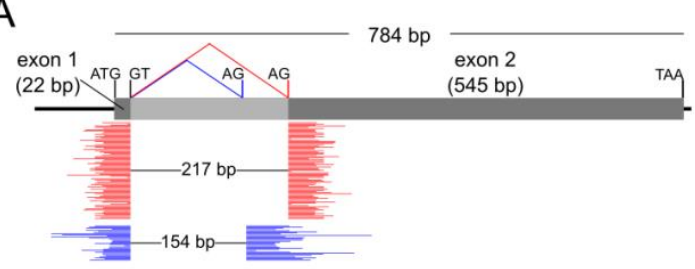

B

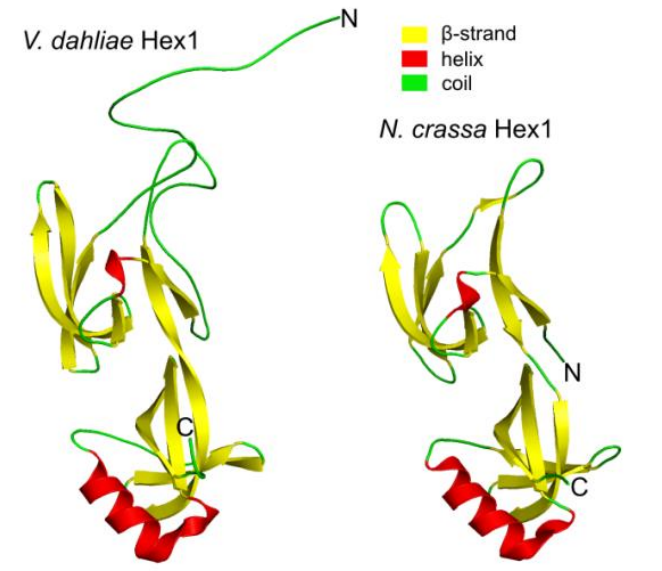

C

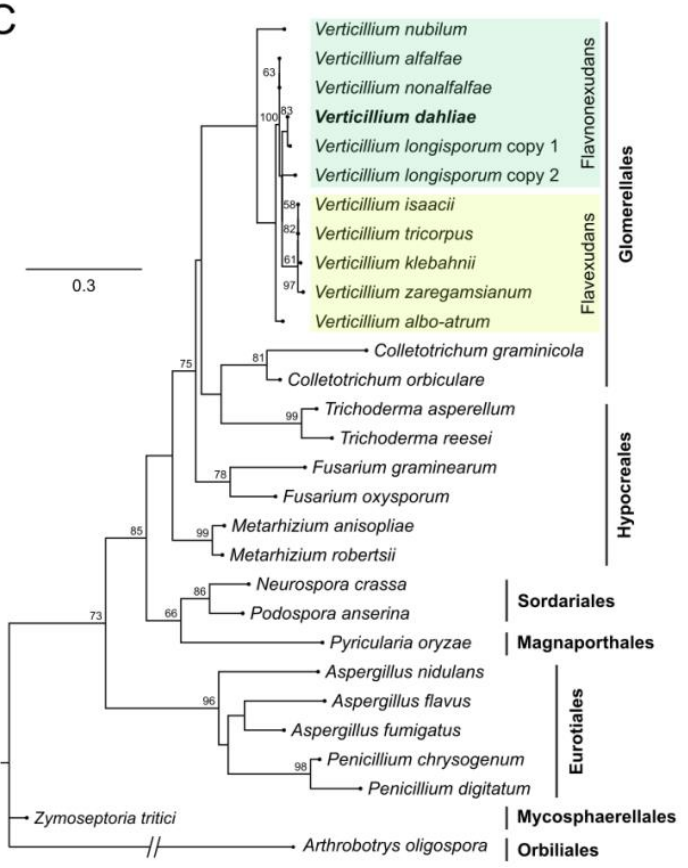

Figure 1. Gene and protein structure of the Hex1 homolog of $V$. dahliae, and phylogenetic analysis. (A) Gene structure of locus VDAG_01749. Mapping of RNA-seq reads on the genomic sequence supports the definition of an intron that can be spliced in two alternative ways (red and blue reads, respectively) to produce two highly similar isoforms of the protein. (B) Prediction by homology modeling of the tertiary structure of $V$. dahliae Hex1 and comparison to the solved structure of its $N$. crassa homolog (PDB $1 \mathrm{KHI}$ ). (C) Maximum likelihood phylogenetic tree of Hex1 homologs across several Pezizomycotina orders of varying phylogenetic distances from Verticillium. The two clades of the Verticillium phylogeny, i.e. Flavnonexudans and Flavexudans, are highlighted in dark and light green, respectively. 


\subsection{Deletion of Vdhex 1 and Morphological and Physiological Characterization}

To determine the functions of Hex1 in $V$. dahliae, a deletion mutant ( $\Delta$ hex1) was constructed through double homologous recombination using Agrobacterium tumefaciens for transforming wild-type conidia (isolate Ls.17). Replacement of the wild-type hex1 gene with the neo cassette (conferring resistance to geneticin) was confirmed using PCR and Southern blot analyses (Figure S2). The full-length hex1 ORF of the wild-type isolate, flanked by $2 \mathrm{~kb}$-long genomic sequences, was amplified and co-transformed with plasmid pUCATPH to generate the complemented strain hex1-c.

When compared to the wild type and the complemented strain, the $\Delta$ hex 1 mutant exhibited significantly slower growth ( $p$-value: $9.0 \times 10^{-4}$ ), more compact aerial mycelium and abnormal colony periphery, both on PDA and MM (Figure 2A-B). Microsclerotia and pigment deposition in the knock-out strain were delayed by 5 days, but after 30 days of growth they were indistinguishable from the other strains. The mutant exhibited significant phenotypic alterations regarding its asexual reproductive capacity. Conidiation was dramatically lower than in the wild type (10fold reduction, $p$-value: $8.7 \times 10^{-7}$; Figure $2 \mathrm{~B}$ ) and the ability of its conidia to germinate was also significantly reduced $\left(15.3 \%\right.$ reduction, $p$-value: $\left.1.8 \times 10^{-5}\right)$ in comparison to the wild type (Figure $2 \mathrm{~B}$ ). Furthermore, we frequently observed abnormal morphologies in $\Delta$ hex 1 germlings, which included bipolar or irregular patterns of germ tube emergence, and faster branching of young germlings (Figure 2C). Mature $\Delta$ hex 1 hyphae and conidiophores also exhibited a distinctive "curly" phenotype in their apical regions, which often appeared wavy and fragile (Figure 2D and Figure S3). All aforementioned phenotypes were fully rescued by complementation of hex1 in the hex1-c strain, confirming their ascription to the hex1 deletion. On the other hand, the mutant's septation pattern was not significantly altered (Figure 2D).

The three strains were subjected to hypotonic shock by immersing their hyphae into distilled water, in order to study their integrity and resilience. Notably, hyphal burst and cytoplasmic leakage were frequently observed only in the $\Delta h e x 1$ strain, mostly at the hyphal tips and rarely at sub-apical compartments, leading sometimes to shrunk hyphae that had lost their cytoplasm (Figure 2E). During live-cell imaging of wild-type hyphae we also often observed spherical vesicles in the vicinity of septae (and rarely close to the cell wall without obvious connection to septae), which were not detected in $\Delta$ hex1. Overall, these results are consistent with the hypothesis that Hex1 in $V$. dahliae is essential for WB formation, which is involved in the maintenance of hyphal integrity, presumably by conditionally sealing the septal pore. 
bioRxiv preprint doi: https://doi.org/10.1101/2020.11.04.367870; this version posted November 4, 2020. The copyright holder for this preprint (which was not certified by peer review) is the author/funder, who has granted bioRxiv a license to display the preprint in perpetuity. It is made available under aCC-BY-NC-ND 4.0 International license.

A
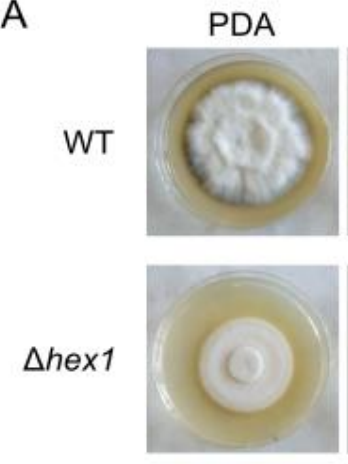

hex1-c

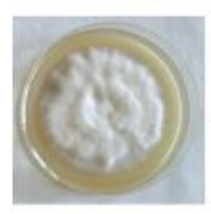

C

WT
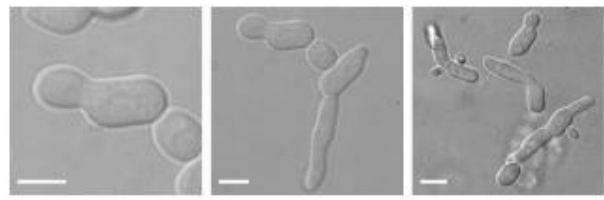

$\Delta h e x 1$
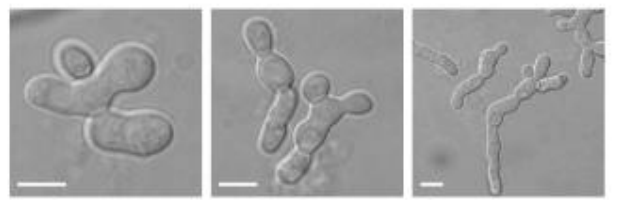

$E$
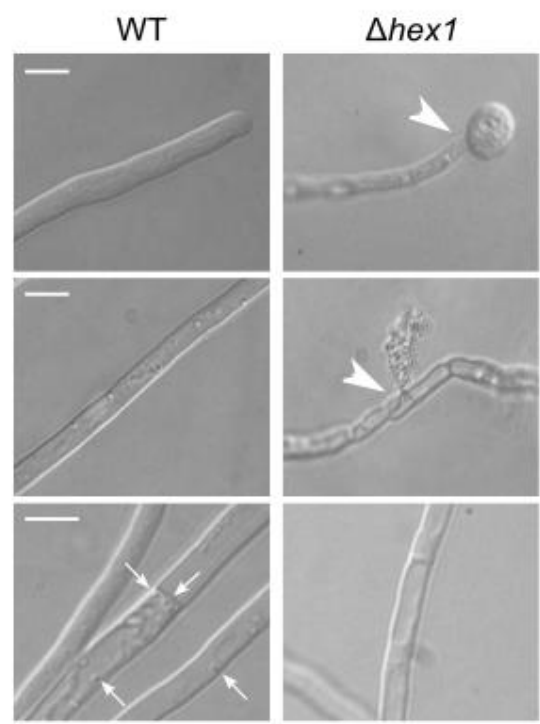

$\Delta h e x 1$
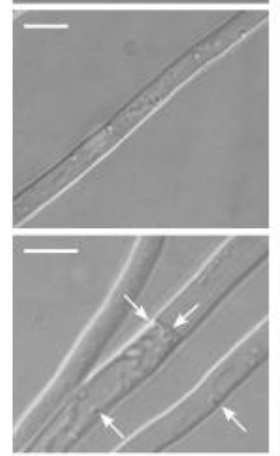

B
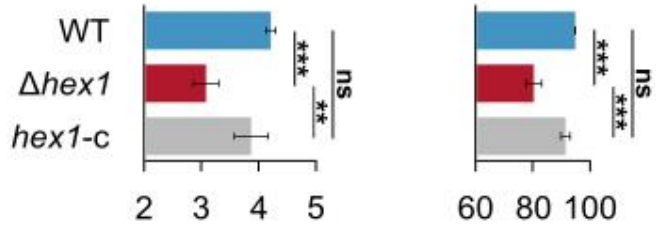

6080100

growth rate $(\mathrm{mm} / \mathrm{d}) \quad \%$ germination

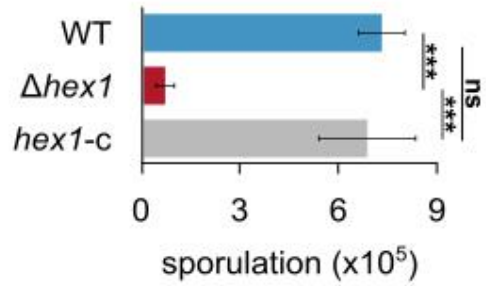

D
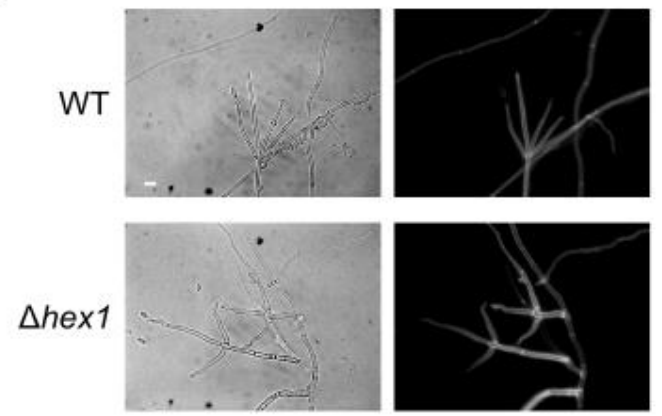

$\mathrm{F}$
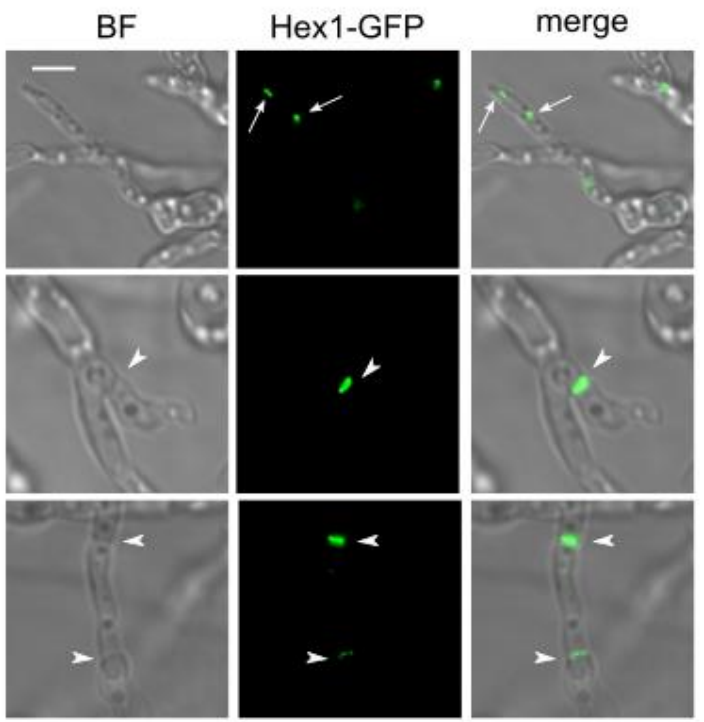

Figure 2. Morphological and physiological characterization of the $V$. dahliae $\Delta$ hex 1 strain. (A) Colony morphologies of the $V$. dahliae wild-type isolate (Ls.17), the deletion mutant $\Delta$ hex1 and the complemented strain hex1-c, after growth of 25 days on PDA, CM and MM. (B) Growth rate, ability of conidia to germinate and abundance of conidial production of the 3 strains. All experiments were performed in triplicate, and 150 conidia were tested for germination per replicate. Bars: SD. Statistical significance of differences was tested by oneway ANOVA, followed by Tukey's post-hoc test $\left({ }^{*} p \leq 0.05\right.$, ${ }^{* *} p \leq 0.01$, ${ }^{* * *} p \leq 0.001$, ns: nonsignificant). (C,D) Microscopic characteristics of conidia (C; bars $=5 \mu \mathrm{m})$ and hyphae (D; cell 
wall staining using calcofluor white M2R; bar $=10 \mu \mathrm{m}$ ) of the wild-type and the $\Delta$ hex 1 strains.

(E) Response of the wild-type and the $\Delta$ hex 1 strains to hypotonic shock by immersing their hyphae to distilled water. Arrowheads: hyphal burst and cytoplasmic leakage. Arrows: Spherical vesicles, usually localized close to the septal wall, that were observed during livecell imaging of the wild-type strain but were absent from $\Delta$ hex1. Bars $=10 \mu \mathrm{m}$. (F) Subcellular localization of the Hex1-sGFP tagged protein in $V$. dahliae. Hex1 is localized either in small globular vesicles (presumably peroxisomes or WBs, indicated by arrows) or at the septal wall (arrowheads). Bar $=5 \mu \mathrm{M}$.

\subsection{Localization of VdHex1 at Septae}

Our finding that the $V$. dahliae Hex1 homolog lacks a polyhistidine motif in its $\mathrm{N}$ terminal region, which has been demonstrated to be involved in septal targeting in $A$. fumigatus [13], motivated us to examine directly its subcellular localization. For this, we constructed a $V$. dahliae strain expressing a Hex1-sGFP construct under the control of its endogenous promoter. Fusion of SGFP at the C-terminus of Hex1 was expected to largely inactivate the terminal peroxisome signal motif [47]. Indeed, vesicles with SGFP signal, presumably corresponding to peroxisomes or WBs, were only relatively rarely observed (Figure $2 \mathrm{~F}$ ). On the other hand, strong fluorescence was often detected at septae; notably, this was not limited to septal pores, but was distributed along the entire septum (Figure $2 \mathrm{~F}$ ). These results directly demonstrate the association of Hex1 with septae in $V$. dahliae, and suggest that different species have probably adopted different mechanisms for targeting Hex1 to the septum.

\subsection{Vdhex 1 is Indispensable for Pathogenicity}

Pathogenicity bioassays on eggplant (cv. Black Beauty), which is highly susceptible to $V$. dahliae [38], were performed to investigate the possible involvement of Hex1 in pathogenicity and virulence of the fungus. Eggplant seedlings were inoculated with the wild-type, $\Delta$ hex 1 and hex1-c strains, and their disease severity was assessed 45 days after inoculation. The $\Delta$ hex 1 mutant caused notably less severe disease compared to the wild-type and hex1-c strains (Figure 3A-B). Only a small percentage of $\Delta$ hex 1 -inoculated plants $(6.7 \%)$ showed severe symptoms (disease severity $>50 \%$ ), while the majority $(86.7 \%$ ) remained symptom-free or exhibited very mild symptoms (disease severity $\leq 20 \%$ ). This was in contrast to the wild type and the complemented strains, which caused severe symptoms to $36.7 \%$ and $30.0 \%$ of plants, respectively, characterized by typical Verticillium-induced symptoms including wilting, chlorosis and defoliation (Figure 3B).

To gain a better understanding of the pathogenic properties of the $\Delta h e x 1$ deletion mutant, we further performed a detailed time-course comparison of virulence between the wild type and $\Delta$ hex 1 over 29 days post-inoculation (Figure $3 \mathrm{C}$ ). Plants inoculated with the wild type started presenting symptoms on the $15^{\text {th }}$ day, and the 
mean disease severity at the end of the experiment was $59.4 \%( \pm 4.7 \%)$. On the contrary, infection with the $\Delta$ hex 1 mutant started causing symptoms only on the $22^{\text {nd }}$ day, reaching a final severity of $9.1 \%( \pm 3.3 \%)$. Calculation of the area under disease progress curve (AUDPC) values, which account for the plant disease progression over 29 days, revealed that the $\Delta$ hex 1 virulence was 16.3 times lower than that of the wild type (Figure 3D). Consistently, the average plant fresh weight of plants treated with $\Delta$ hex 1 was significantly lower than that of plants treated with the wild type (Figure 3E). Finally, we investigated the presence of the fungus within plant tissues by attempting to re-isolate it from xylem sections of the infected plants, at the end of the experiment. The re-isolation ratio of $\Delta$ hex 1 was reduced by $49.4 \%$ in comparison to the wild type $(0.41 \pm 0.09$ and $0.81 \pm 0.08$, respectively; Figure $3 F)$, which corroborates the difference observed in disease severity and demonstrates the difficulty of the $\Delta$ hex 1 mutant to colonize the xylem and cause systemic infection of the plants.

A

$\%$ disease severity $0=1-20=21-50=51-75=76-100$

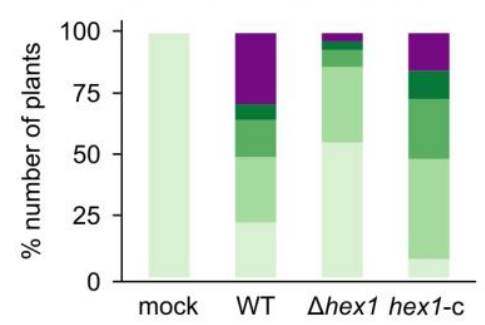

C

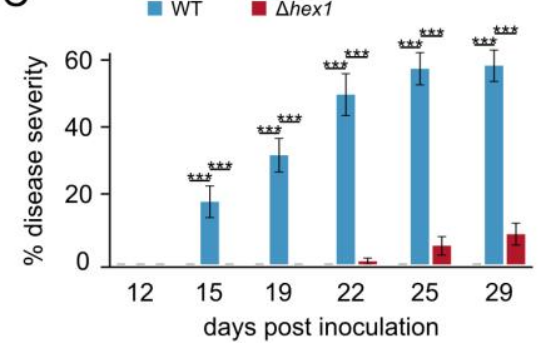

B

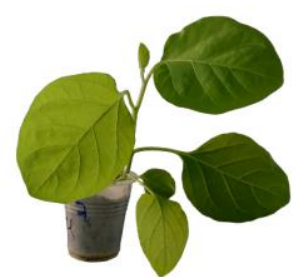

mock

D

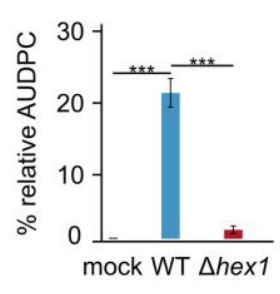

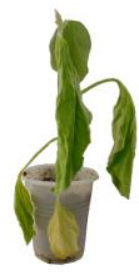

WT

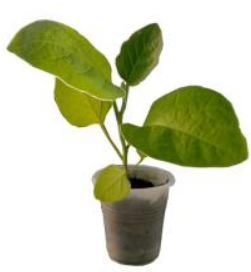

$\Delta h e x 1$

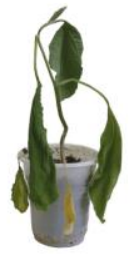

hex1-c
E

$\mathrm{F}$
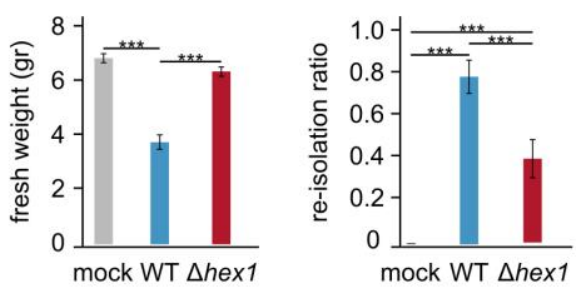

Figure 3. Phytopathological characterization of the $V$. dahliae $\Delta$ hex1 strain. (A) Disease severity of the wild-type (WT), the deletion ( $\Delta$ hex1) and the complemented (hex1-c) strains, 45 days post-inoculation on eggplant seedlings (30 plants/strain). Uninfected plants (mock) served as control. (B) Representative plants are shown for each strain. (C) Time-course comparison of disease severity between the wild type and $\Delta$ hex1 (21 plants/strain) over 29 days post-inoculation. (D-F) Mean relative AUDPC scores, plant fresh weights and fungal reisolation ratios at the end of the time-course experiment. Bars $=\mathrm{SE}$. Statistical testing by oneway ANOVA followed by Tukey's post-hoc test $\left({ }^{* * *} p \leq 0.001\right)$. 
3.5. VdHex1 is Involved in the Fungal Response to Osmotic Stress and Cell Wall/Plasma Membrane-Perturbating Agents

Based on our previous findings and the demonstrated functions of Hex1 and WBs in other fungi [27], we supposed that the Hex1 homolog of $V$. dahliae might also be involved in environmental stress responses and the maintenance of cellular integrity. To test this, we exposed the deletion mutant $\Delta h e x 1$ to hyperosmotic stress and a variety of cell wall-perturbating or damaging substances, and we compared its responses to those of the wild type by spot dilution assays and radial growth analyses. Upon treatment with either $\mathrm{NaCl}$ or sorbitol, the $\Delta$ hex1 strain achieved significantly reduced growth in comparison to the wild type, even though germination was not severely affected (Figure 4A-B). Microscopic observation of the two strains after growth in a hyperosmotic medium of $0.5 \mathrm{M} \mathrm{NaCl}$ revealed that many $\Delta$ hex 1 germlings exhibited hyphal bleeding of their cytoplasm, and the majority of them were entirely permeable to methylene blue, which stains dead cells. On the contrary, wildtype cells remained mostly unstained, or only one compartment allowed accumulation of the dye, while the remaining hypha was unaffected (Figure 4C). This suggests that Hex1 is involved in hyphal compartmentalization and ensures cell heterogeneity, presumably by occluding septal pores upon osmotic stress to protect the rest of the hypha from destruction. Furthermore, hyperosmotic conditions induced increased septation in $\Delta$ hex 1 and also increased the frequency of "curly" hyphae with branching and the appearance of "bubble"-like cells, only in the mutant (Figure 4C). These findings are further suggesting high sensitivity of $\Delta$ hex 1 cells to osmotic stress. 
A

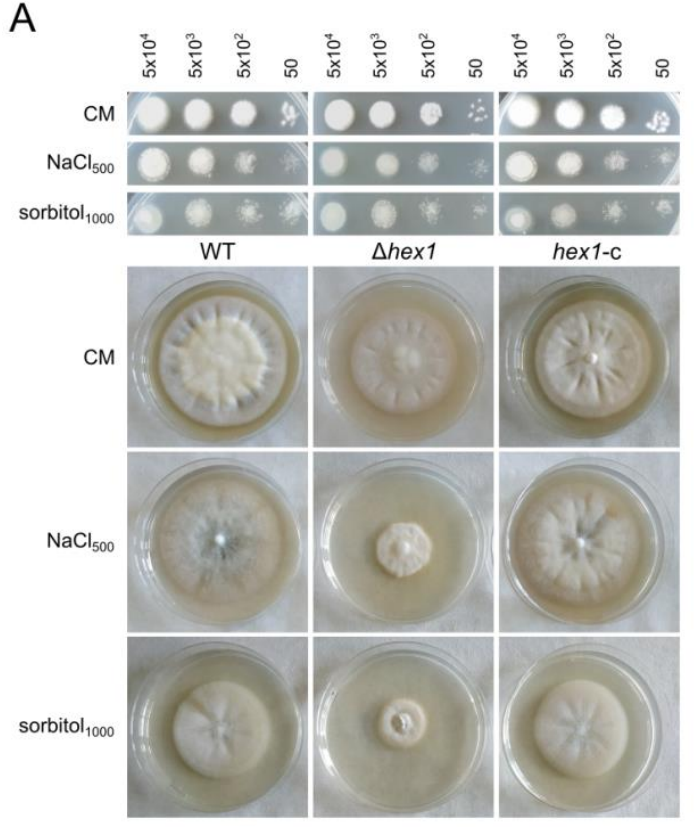

B

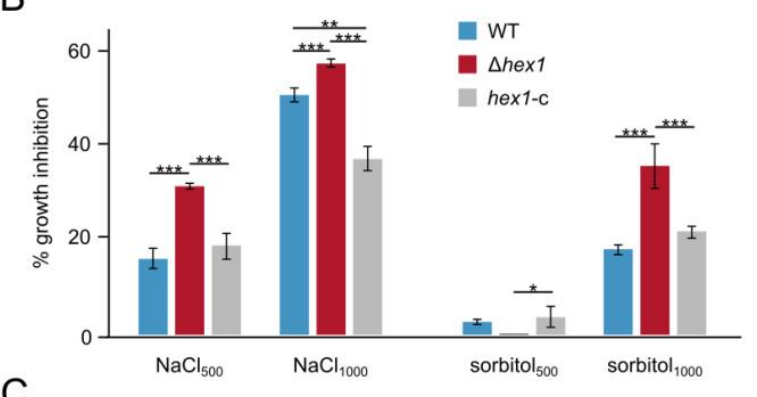

C

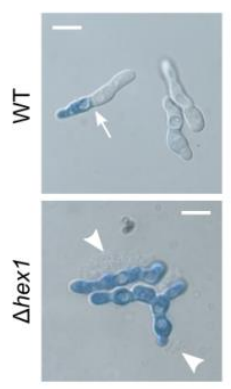

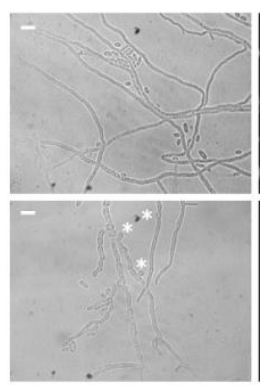

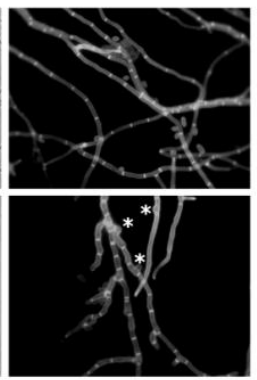

Figure 4. Effects of hyperosmotic stress on $\Delta$ hex1. (A) Responses of the wild-type, the deletion $(\Delta h e \times 1)$ and the complemented (hex1-c) strains to $\mathrm{NaCl}$ and sorbitol, as regards germination (top; the number of inoculated conidia per spot are provided above the images; growth for 3 days) and radial growth (bottom; growth for 18 days). (B) Relative growth inhibition by $\mathrm{NaCl}$ and sorbitol (each condition was tested in triplicate; bars = SD; statistical testing by one-way ANOVA followed by Tukey's post-hoc test $\left({ }^{*} p \leq 0.05,{ }^{* *} p \leq 0.01,{ }^{* * *} p \leq\right.$ 0.001). All concentrations are given in $\mathrm{mM}$. (C) Staining of wild-type and $\Delta$ hex 1 germlings with methylene blue, after growth for $16 \mathrm{~h}$ in a hyperosmotic medium of $0.5 \mathrm{M} \mathrm{NaCl}$ (left). Arrow: septum; Arrowheads: cytoplasmic bleeding. Morphology of corresponding hyphae under the same conditions. Asterisks: "bubble"-like cells. Cell wall staining using calcofluor white M2R. Bar $=10 \mu \mathrm{m}$.

Calcofluor white, Congo red and SDS were used to test the sensitivity of the $\Delta$ hex 1 mutant to cell wall and membrane-damaging agents. Germination frequency of the mutant was reduced and its radial growth was significantly limited upon exposure to calcofluor white and Congo red, suggesting drastically reduced tolerance against cell wall stress (Figure 5A-B). Similar effects were observed when we tested the antifungal agents amphotericin $B$ and the acyclic sesquiterpene alcohol farnesol, which target sterol biosynthesis and membrane integrity (Figure 5A-B). Fluconazole was also tested but seemed to affect equally the wild type and the deletion mutant (Figure S4).

Finally, we tested a number of substances that are present in commercially available fungicides as inhibitors of fungal sporulation and germination (cymoxanil, fosetyl-AI, mandipropamid and cyflufenamid). All of them affected similarly the mutant and the control strains (Figure S4). 
A

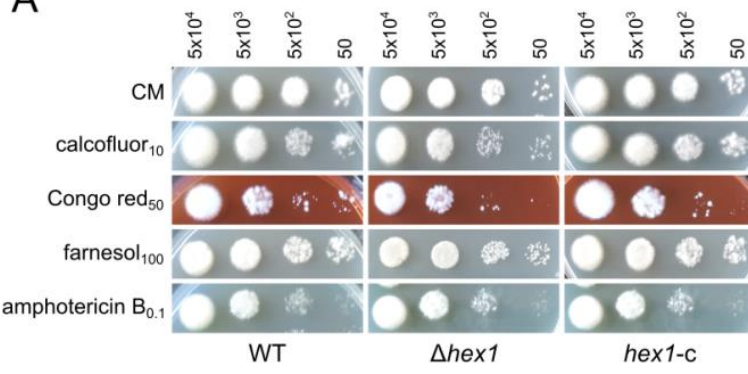

B
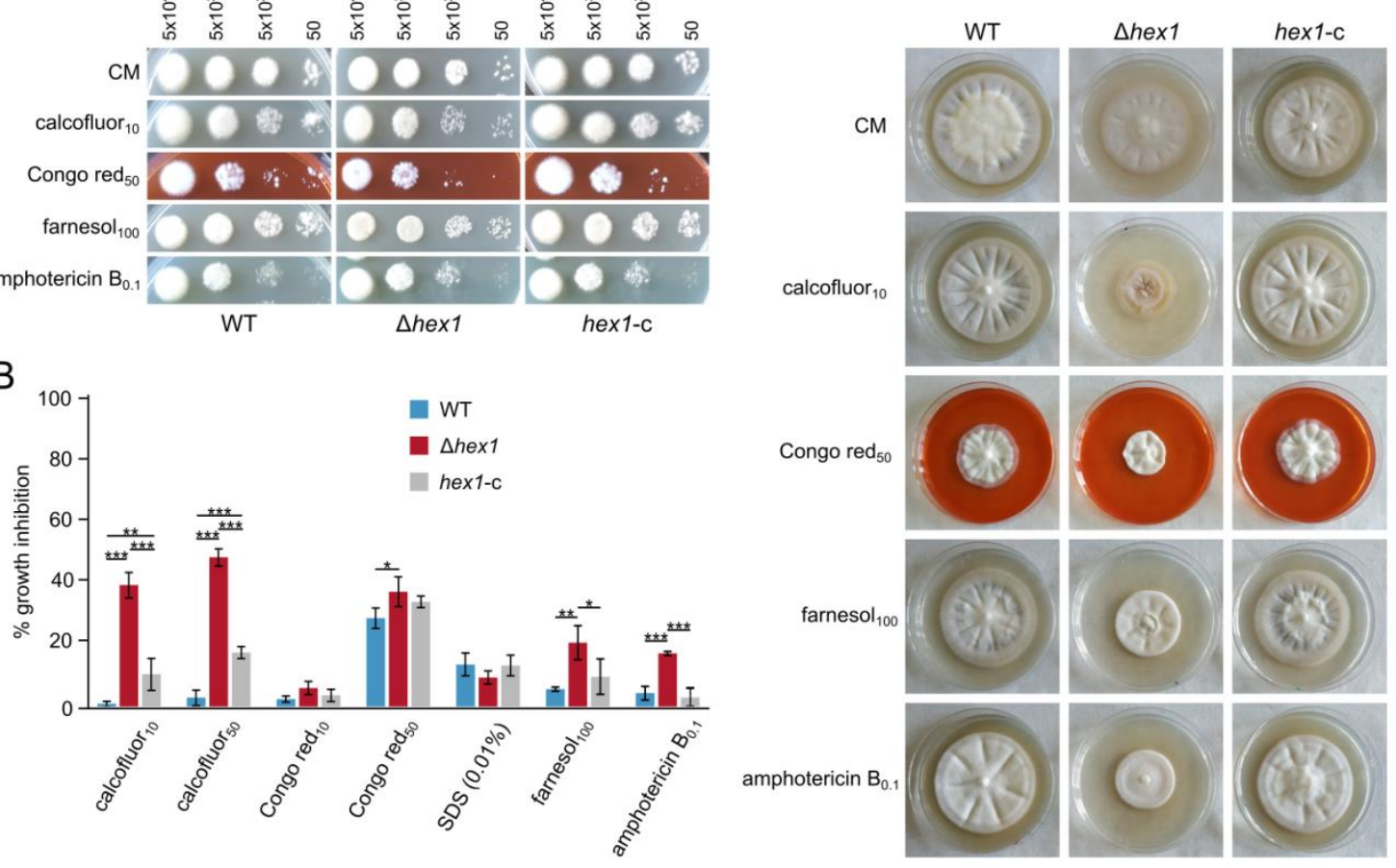

Figure 5. Effects of cell wall and plasma membrane stress on $\Delta$ hex1. (A) Responses of the wild-type, the deletion ( $\Delta$ hex1) and the complemented (hex1-c) strains to calcofluor white M2R, Congo red, SDS, farnesol and amphotericin B as regards germination (top; the number of inoculated conidia per spot are provided above the images; growth for 3 days) and radial growth (right; growth for 18 days). (B) Relative growth inhibition by the same substances (each condition was tested in triplicate; bars $=\mathrm{SD}$; statistical testing by one-way ANOVA followed by Tukey's post-hoc test $\left({ }^{*} p \leq 0.05,{ }^{* *} p \leq 0.01,{ }^{* * *} p \leq 0.001\right)$. All concentrations are given in $\mu \mathrm{g} / \mathrm{mL}$.

\subsection{VdHex1 is Required for Normal Response to Oxidative Stress and ROS Metabolism}

Understanding of the strategies that organisms have evolved to cope with oxidative stress on one hand, and to use Reactive Oxygen Species (ROS) as important signaling components in developmental regulation on the other, are of fundamental interest; this becomes especially relevant in the case of pathogens, which need efficient mechanisms to counteract host-induced oxidative responses $[48,49]$. Since the role of Hex1 in response to oxidative stress is not well established, we used the oxidative agents $\mathrm{H}_{2} \mathrm{O}_{2}$, the herbicide paraquat and iprodione (i.e., a broad-spectrum antifungal drug that blocks germination and causes oxidative damage), as well as $\mathrm{N}$-acetyl cysteine as ROS scavenger, to examine the possible involvement of the protein in the resistance of the fungus to ROS. Treatment with any of the three ROS-inducing substances resulted in significant growth inhibition of the $\Delta$ hex1 mutant and induced pigmentation only in the wild-type and complemented 
bioRxiv preprint doi: https://doi org/10.1101/2020.11 04 367870; this version posted November 4, 2020. The copyright holder for this preprint (which was not certified by peer review) is the author/funder, who has granted bioRxiv a license to display the preprint in perpetuity. It is made available under aCC-BY-NC-ND 4.0 International license.

strains, while iprodione additionally caused a drastic reduction in germination frequency, particularly in $\Delta$ hex1 (Figure 6A-B).

To further investigate how Hex1 possibly affects ROS levels under different types and levels of stress, we used a histochemical method of NBT staining to detect superoxide radicals $\left(\mathrm{O}_{2}^{-}\right)$in the mycelium. We indeed observed a distinctly different behavior regarding ROS accumulation between the wild type and $\Delta$ hex 1 . Under standard conditions (CM), as well as upon treatment with the stressors paraquat and farnesol, the mutant displayed significantly more limited ROS levels, restricted to a narrow peripheral mycelial area of active hyphal growth (Figure 6C). In sharp contrast, exposure to hyperosmotic stress $(\mathrm{NaCl}$ or sorbitol) resulted in drastically elevated ROS levels, throughout the colony. These findings suggest important roles of Hex1 in the regulation of ROS metabolism as a function of environmental stress.

A
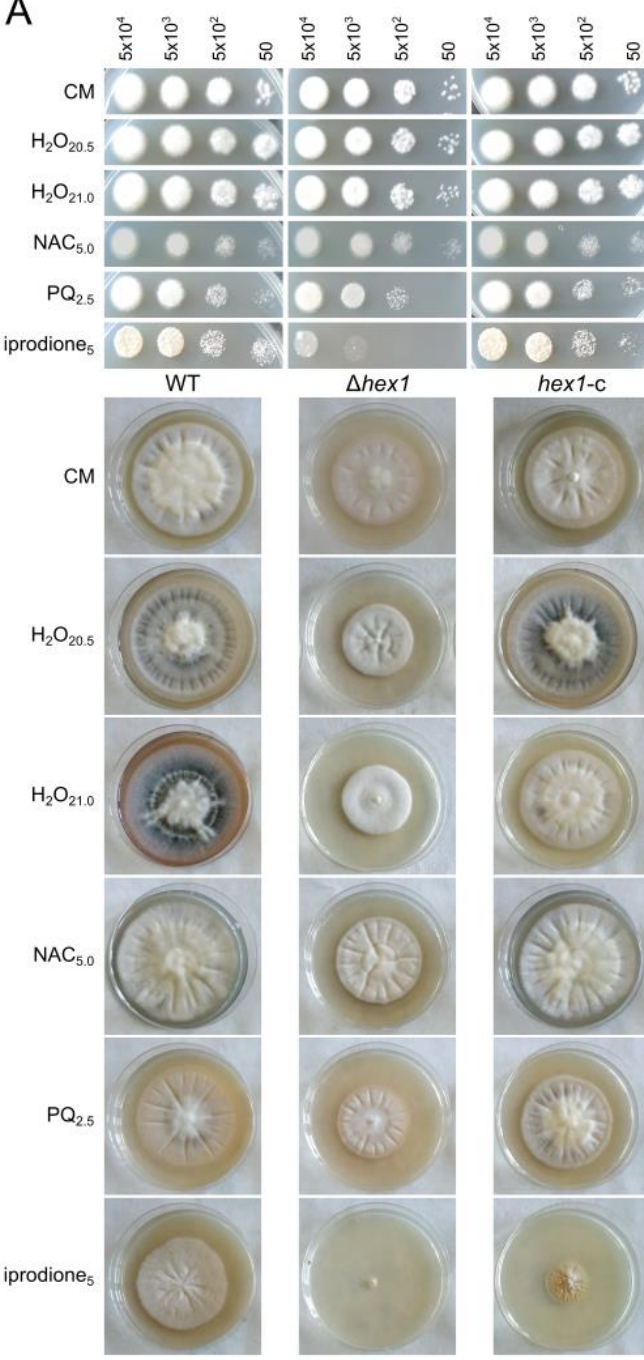

B

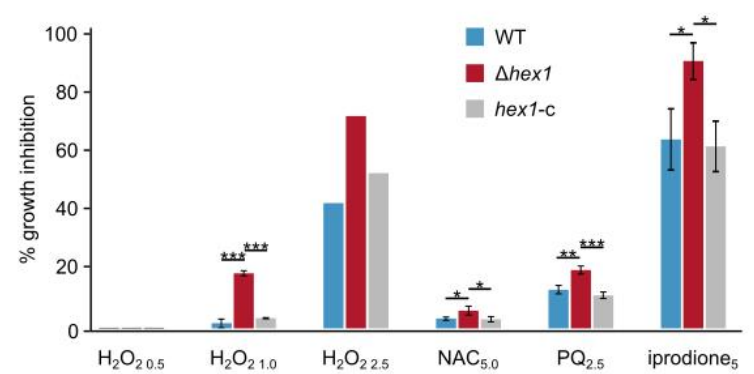

C

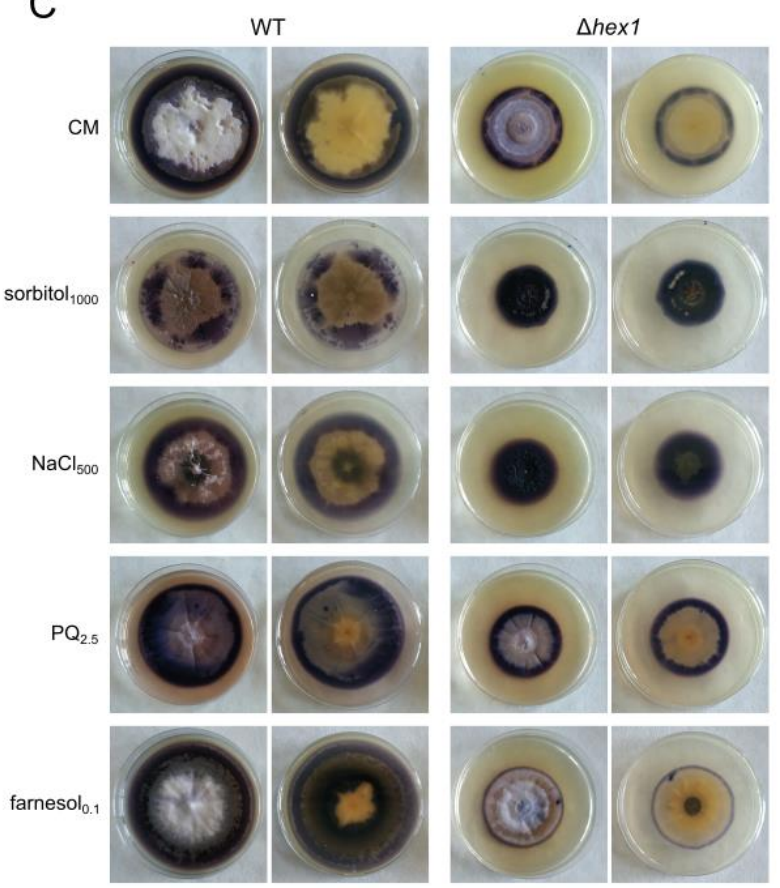

Figure 6. Effects of oxidative stress on $\Delta$ hex1 and its involvement in ROS metabolism. (A) Responses of the wild-type, the deletion ( $\Delta$ hex1) and the complemented (hex1-c) strains to $\mathrm{H}_{2} \mathrm{O}_{2}$, paraquat, iprodione and $\mathrm{N}$-acetyl cysteine as regards germination (top; the number of 
inoculated conidia per spot are provided above the images; growth for 3 days) and radial growth (bottom; growth for 18 days). (B) Relative growth inhibition by the same substances (each condition was tested in triplicate; bars $=\mathrm{SD}$; statistical testing by one-way ANOVA followed by Tukey's post-hoc test $\left({ }^{*} p \leq 0.05,{ }^{* *} p \leq 0.01,{ }^{* * *} p \leq 0.001\right)$. All concentrations are given in $\mathrm{mM}$, except for iprodione $(\mu \mathrm{g} / \mathrm{mL})$. (C) Detection of superoxide anion radicals $\left(\mathrm{O}_{2}{ }^{-}\right)$ using NBT staining in colonies of the 2 strains upon treatment with various sources of stress $(\mathrm{NaCl}$, sorbitol, paraquat and farnesol). Both top and bottom view of plates are shown for every treatment.

\subsection{VdHex1 is not Involved in Heterokaryon Incompatibility}

Vegetative fusion of hyphae from different individuals to the formation of heterokaryons is strictly regulated by heterokaryon incompatibility systems. If the two fusion partners have genetic differences in their het loci, the heterokaryotic cell compartment is isolated from the rest of the mycelium and often destroyed through a targeted cell death reaction [7]. Based on our findings, which suggest that Hex1 and WBs of $V$. dahliae are involved in hyphal compartmentalization, presumably by conditionally sealing septal pores upon mechanical damage or environmental stress, we hypothesized that they might also be responsible for the isolation of heterokaryotic cells when incompatibility reactions are triggered. To investigate this possibility, we first checked whether hex1 in $V$. dahliae is required for hyphal fusion or involved in the control or activation of the heterokaryon incompatibility reaction per se. For this, we used the $\Delta$ hex 1 deletion mutant in compatibility assays with standard tester strains from all known compatibility groups of $V$. dahliae (VCGs). In these tests, complementary nitrate non-utilizing (nit) mutants of tested isolates are used in pairings on medium which would support only heterokaryotic growth. Therefore, nit1 and nitM mutants of the $\Delta$ hex 1 strain of isolate Ls.17 were generated and used in assays with complementary nit mutants of 23 wild-type isolates of all compatibility groups; self-pairings (i.e., with independent nit mutants of the same wild-type isolate, Ls.17) were also performed as controls (Table S4). The results are summarized in Table S4. Mutants of the $\Delta$ hex 1 strain were compatible with each other and gave rise to robust heterokaryons, suggesting that hex1 is not required for hyphal fusion. Mutants of both the wild-type isolate Ls.17 and its $\Delta$ hex 1 descendant exhibited strong reactions with members of the same compatibility group, as expected, and also weaker or inconsistent interactions with members of other groups, which is often observed in this species [40]. No difference in the compatibility profile of the $\Delta h e x 1$ mutant was recorded, suggesting that the gene is not involved in the genetic control of heterokaryon incompatibility.

We then addressed our hypothesis that Hex1 might be involved in the containment of the incompatibility-induced catastrophic reaction to the heterokaryotic cell, by time-lapse live-cell imaging of fusion events between incompatible strains. We chose the wild-type isolate BB, which is incompatible with Ls.17, and we also 
deleted its hex1 gene, using the same strategy as for our reference strain (Figure S2). In addition, we labeled the nuclei of BB by tagging its histone $\mathrm{H} 1$ with sGFP and the cytoplasm of Ls.17 with cytoplasmically localized SGFP. This would permit the direct microscopic identification of the two strains in pairings and detection of fusion events between the two. Using this strategy and the two engineered strains, we detected eight independent fusion events between the two incompatible strains and recorded time-lapse movies ( $24 \mathrm{~h}$ ) to study the cell fate upon fusion. In all cases, fusion was followed by gradual nuclear degradation and cell shrinkage, which are typical manifestations of heterokaryon incompatibility-induced cell death [7] (Figure 7A). These processes were always confined to the heterokaryotic cell, and they never affected the adjacent cell compartments (Figure 7A; movie S1). These results suggest that WBs and their major component, Hex1, are not necessary for septal pore plugging in response to the activation of heterokaryon incompatibility cell death reactions. On the other hand, in all of these cases staining with calcofluor white indicated highly increased chitin deposition on the septae which surround the heterokaryotic cell that is destroyed (Figure 7A-B; Figure S5; movie S2), and also on the cell wall of the compartment (Figure S5). Although it is not clear whether this has a role in the reaction or is just a consequence, a reasonable hypothesis is that this extreme thickening of septae might be ensuring the efficient sealing of the heterokaryotic cell and preventing the diffusion of cell death mediators to the adjacent cells.

Finally, based on the established functions of WBs in controlling traffic through the septal pore of fungi, we contemplated that they could also be involved in the control of nuclear migration, an essential step to the formation of heterokaryons through hyphal fusions. However, microscopic examination of the BB $\Delta$ hex 1 strain with SGFP-labeled nuclei revealed that essentially all hyphal compartments were strictly uninucleate (Figure S6), with the exception of the actively dividing cells at hyphal tips, which can transiently have more than one nuclei until the formation of the new septum. This was also the case in the wild-type strain. We rarely observed nuclei migrating through the septal pore, both in wild-type and in $\Delta$ hex 1 hyphae (movie S3). A possible explanation for the fact that binucleate cells are, nevertheless, never observed in the mycelium could involve degradation of one of the nuclei upon migration [50]. 
A

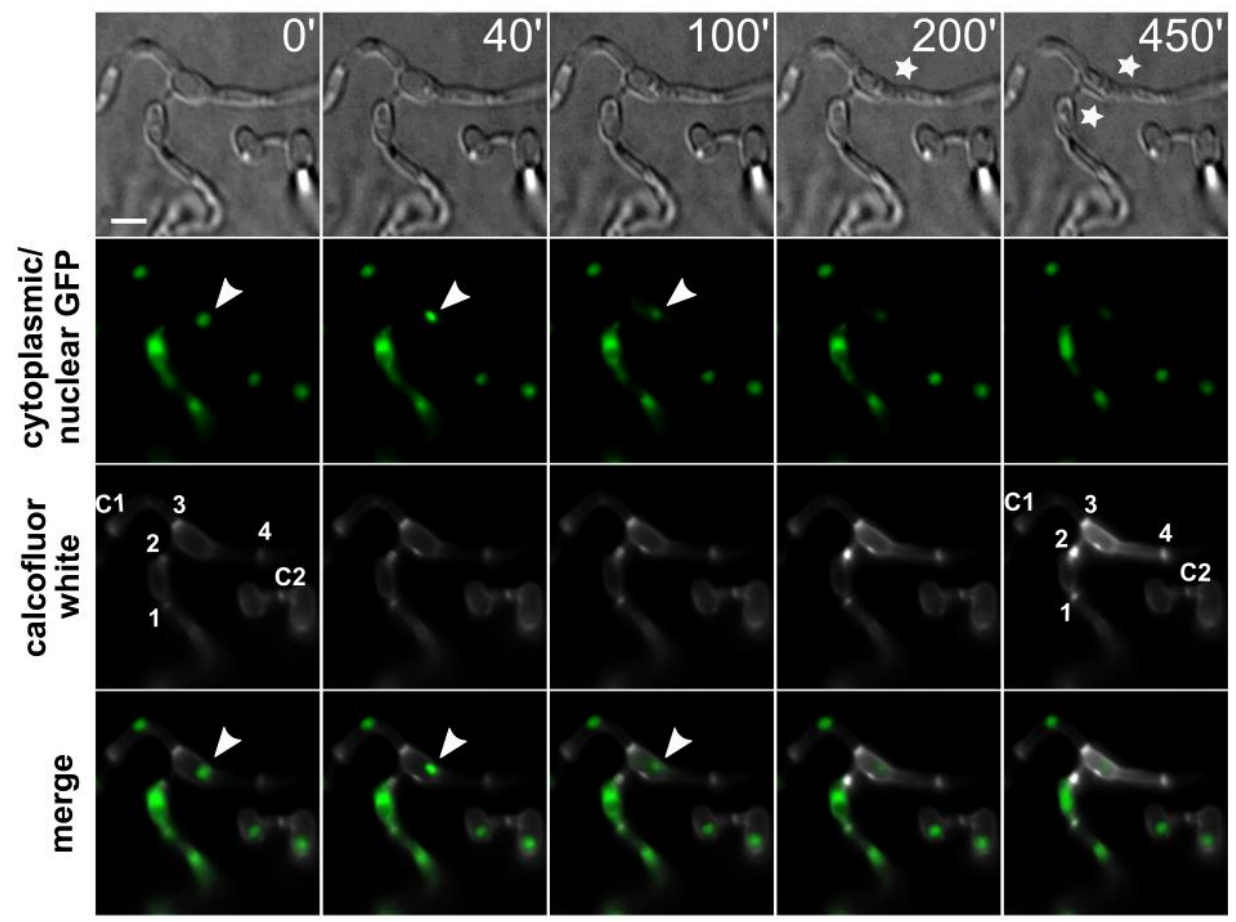

B
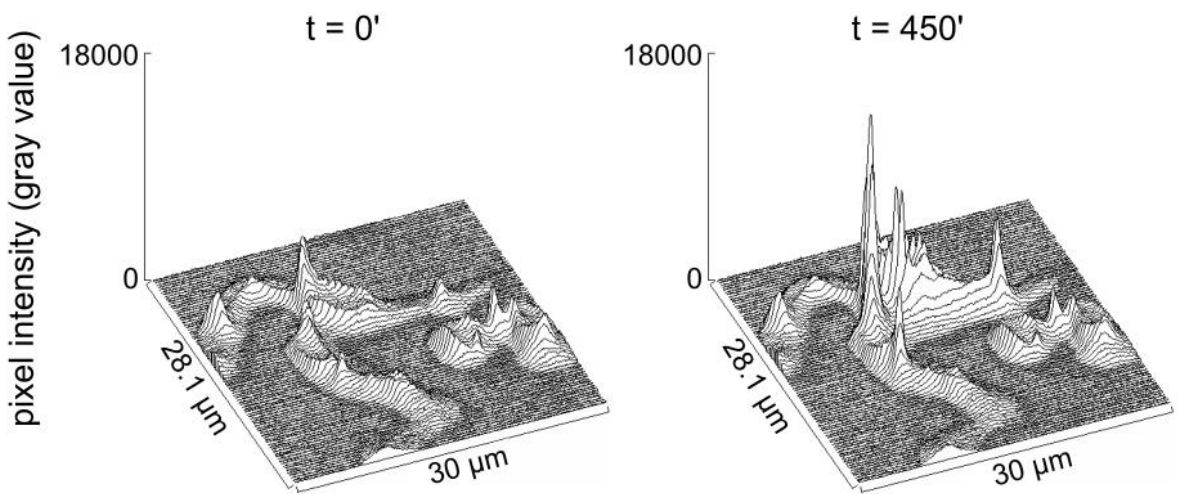

Figure 7. Vdhex1 is not involved in heterokaryon incompatibility. (A) Time-lapse microscopic examination of a fusion event between the incompatible strains BB $\Delta$ hex1 H1-sGFP and Ls.17 sGFP. Typical characteristics of incompatibility-induced cell death, namely nuclear degradation (arrowheads) and cell shrinkage (asterisks) are observed. Septae that surround the fused cells are indicated by numbers 1-4, and two control septae in neighboring hyphal compartments by $\mathrm{C} 1-\mathrm{C} 2$ (see also Figure S5). Cell wall staining was performed using calcofluor white M2R. Bar = $10 \mu \mathrm{m}$. (B) Quantification of blue fluorescence intensity (calcofluor white M2R staining of cell wall chitin) in the region of interest shown in panel $A$, for two post-fusion time points, before and after the visible effects of the incompatibility reaction, respectively. 


\section{Discussion}

Multicellularity has independently evolved from unicellular ancestors on several occasions in different eukaryotic lineages, in multiple ways and with diverse outcomes [51]. In filamentous fungi, these transitions led to the evolution of the mycelium, a syncytial network of interconnected tubular cells (hyphae), resulting from their apical growth, branching and fusion [52]. Cytoplasmic continuity is a defining characteristic of the fungal mycelium and ensures efficient translocation of nutrients and genetic resources [53] and coordination of responses to environmental changes [54], without the need for a dedicated vascular system. Nevertheless, uncontrolled intercompartmental traffic would lead to increased exposure to biotic and abiotic risks that could rapidly propagate throughout the mycelium, such as cytoplasmic leakage due to mechanical damage or fast spread of parasitic genetic elements [3-7]. This underlines the necessity for a trade-off between continuity and conditional control of exchanges in complex organisms. Indeed, fungal evolution has invented structures and mechanisms that address this need, which include compartmentalization of hyphae with septae in higher fungi (ascomycetes and basidiomycetes) [2] and highly regulated mechanisms for the control of cytoplasmic flow through septal pores [8]. In ascomycetes, the peroxisome-derived WBs are involved in this process of plugging septal pores as a response to mechanical or other stimuli $[9,27,55]$.

The major component of WBs was shown to be the conserved peroxisomal protein Hex1 in $N$. crassa $[15,17]$. Its discovery was followed by detailed analyses of its structure and functions, mostly in this and to a lesser extent in other fungi $[13,16,18,20,26]$. In this study, we identified the single Hex1 homolog of $V$. dahliae, a plant pathogen with a particularly broad range of hosts and significant economic impact [28]. A careful study of the deposited gene model, based on automatic annotation, led us to revise the exon-intron boundaries of the gene and further revealed that it is subject to alternative splicing; a process that appears to be very common in $V$. dahliae [56] and which, specifically for hex1, has also been reported in certain other fungi [17-19]. The expression of two protein isoforms has also been experimentally demonstrated in other species using Hex1-specific antibodies $[17,18,21]$, which corroborates our suggestion. The inaccuracy of automatic gene annotation in this case might explain the predicted hypervariable $\mathrm{N}$-terminal extensions observed in many sequences from different species [25,26], indicating that this data should be treated with caution.

Woronin bodies are peroxisomal vesicles with a dense core of self-assembled Hex1 into a crystal lattice [16]. Both $V$. dahliae isoforms of Hex1 were predicted to adopt essentially the same tertiary structure as their $N$. crassa homolog [16], with the exception of the $\mathrm{N}$-terminal region, which is extremely variable in sequence between fungi and seems to remain in a disordered state. Typical peroxisomal targeting signal peptides [47] were detected at their C-termini, and the conserved histidine residue that is necessary for crystallization of the protein is also present [16]. None of the isoforms has a poly-histidine motif in the variable $\mathrm{N}$-terminal region, which in $A$. 
fumigatus is necessary for septal targeting of Hex1 [13]. However, such motifs are also absent from other Hex1 homologs, including that of $N$. crassa [17]. Moreover, Cterminal tagging of the $V$. dahliae Hex1 with sGFP demonstrated that Hex1 is still targeted to the septum, despite the lack of this motif. Overall, these findings suggest that more than one mechanisms mediate septal targeting of Hex1 in fungi. Based on this localization pattern and the well established role of Hex1 in septal pore plugging, we investigated the resilience of mutant $\Delta$ hex 1 hyphae. In full concordance with its expected function, the lack of Hex1 rendered $V$. dahliae hyphae prone to excessive hyphal bleeding upon hypotonic shock-induced hyphal damage. This suggests defects in hyphal compartmentalization due to dysfunctional septal pore sealing.

Growing evidence from various fungi indicates that apart from its defining role in septal plugging upon damage, Hex1 has pleiotropic phenotypes in fungal morphology and physiology $[13,17,18,22,26]$. Some of these reports present contradictory results regarding particular phenotypes in different species, including growth characteristics and pathogenicity. This suggests species- or lineage-specific variability in Hex1mediated processes and underlines the importance for functional investigations of new Hex1 homologs. These considerations served as our motivation to investigate a number of hypothesized roles of Hex1 in physiology, pathogenicity, stress response, ROS metabolism and heterokaryon incompatibility in $V$. dahliae. Our results strongly confirm the multifaceted involvement of Hex1 in several fundamental processes in this fungus. Deletion of hex 1 led to reduced growth rate, similarly to $N$. crassa $[15,17]$ and Arthrobotrys oligospora [24], but unlike several other fungi, in which deletion of the gene did not result in growth defects [18,21,22,25]. The absence of Hex1 from $V$. dahliae also resulted in drastic reduction in conidiogenesis, which has been generally observed $[17,22,24,25]$. Furthermore, we identified in $V$. dahliae developmental phenotypes that were hitherto unknown for this gene, namely restricted and abnormal conidial germination, increased hyphal branching, "curly" hyphal tips and "bubble"-like cells. Collectively, V. dahliae Hex1 appears to have significant contributions in a number of fundamental processes which are related to asexual reproduction, hyphal development, and possibly cell wall deposition and cellular polarity. An enrichment of WBs in the apical region of germ tubes and hyphal tips has been described in $N$. crassa and $A$. nidulans $[11,57,58]$, and their peroxisomeunassociated apical clustering has been shown in $A$. fumigatus [21]. These resemble the localization pattern of the Spitzenkörper, the organizing center of hyphal growth that coordinates the vesicle-mediated delivery of cell wall material to the apical cell surface [59]. These observations and the pleiotropic growth phenotypes that we report here open up the possibility that Hex1 and WBs might have multiple cellular roles in growth and morphogenesis of $V$. dahliae and other fungi, some of which might be independent from their established role in septal pore occlusion upon damage; a hypothesis that welcomes future investigation.

Motivated by the identification of phenotypes in $\Delta h e x 1$ cells that suggest reduced cell wall robustness, including the detection of hyphal bleeding from internal compartments upon hypotonic shock and the "curly" hyphal tips that were often 
observed, we further investigated the responses of the mutant strain to osmotic stress and to factors that affect cell wall and membrane integrity. We found that apart from a significant growth inhibition, presumably due to the reduced ability of the hyphae to isolate their damaged cellular compartments, hyperosmotic conditions also caused increased septation and frequent appearance of morphological alterations, further supporting the hypothesis that Hex1 has significant contributions to the regulation of colony morphogenesis. Moreover, our experiments demonstrated that Hex1 in $V$. dahliae mediates resistance against common fungicides that target the cell wall and the plasma membrane. In the absence of Hex1, we observed reduced germination of conidia and growth rate upon treatment with either calcofluor white or Congo red, which indicates that changes in cell wall structure and related defects in hyphal integrity possibly result in impaired germination. Contrasting results have been reported as regards to the sensitivity of $\Delta$ hex 1 mutant strains of other fungi to osmotic and cell wall/plasma membrane stress; deletion of the gene did not significantly affect $M$. robertsii and $A$. flavus [25,26], whereas in $A$. fumigatus and Arthrobotrys oligospora it had a significant impact [13,24].

We further hypothesized and investigated whether Hex1 could be involved in the fungal response to oxidative stress and ROS metabolism. The mutant strain indeed exhibited growth defects in coping with increased oxidative damage induced by treatment with $\mathrm{H}_{2} \mathrm{O}_{2}$ and paraquat, but also with amphotericin $\mathrm{B}$, farnesol and iprodione, but not fluconazole. This may indicate that germination might be affected not only by inhibition of ergosterol biosynthesis, but also by the oxidative damage that these factors can cause. Furthermore, NBT staining of superoxide in the mycelium indicated altered levels of ROS accumulation, both under standard conditions and in the presence of high oxidative load. Osmotic stress caused increased ROS accumulation in the $\Delta$ hex 1 mycelia and this could possibly explain the significant developmental defects in these conditions. On the other hand, in the presence of farnesol, $\Delta$ hex 1 exhibited lower ROS generation.These findings open up the possibility that Hex1 plays a significant role in ROS metabolism and resistance to oxidative stress in $V$. dahliae. Considering the significance of intracellular ROS in signaling and regulatory functions [60], such a connection with Hex1 might be of particular interest. Furthermore, it possibly becomes especially relevant in pathogenic fungi, which need to cope with host responses to infection that often involve bursts of ROS generation [48,49]. In the pathogenic fungi Alternaria brassicicola and $A$. fumigatus, WBs were shown to be associated with the redox homeostasis-related transmembrane protein TmpL [61], which could be consistent with a function of Hex1 in ROS metabolism. To our knowledge, we report here the first experimental data that suggest an important role of Hex1 in ROS homeostasis.

Considering the pleiotropic and significant effects that Hex1 deletion has on fungal growth and development, one could reasonably further assume a possibly important role in pathogenicity. This has been investigated in several plant and other pathogens, and results between species are contradicting, demonstrating partial attenuation of virulence to varying degrees in some cases $[13,18,22,25]$, but no 
compromise in pathogenic capacity in others $[23,26]$. We report here for $V$. dahliae one of the most pronounced roles of Hex1 in fungal pathogenicity. Deletion of hex 1 diminished virulence of $V$. dahliae on eggplant, a very susceptible host of this pathogen [38]. Consistently with this drastically reduced disease severity by $84.7 \%$ on average, presence of the fungus in the xylem of infected plants was also reduced by $49.4 \%$. These results suggest that Hex 1 is required not only for penetration of roots by $V$. dahliae, but also for its propagation in the host and its ability to cause systemic infection. It is reasonable to assume that this drastic reduction of virulence could be linked to the pleiotropic defects of $\Delta h e x 1$ in $V$. dahliae growth, physiology and stress response, rather than to solely attribute the attenuated virulence to an independent role of Hex1 in pathogenicity. The infection cycle of $V$. dahliae begins with germination of microsclerotia, elongation of hyphae and penetration of roots. In this endeavor, hyphal integrity is indispensable for efficient attack to the plant [62]. We demonstrated that deletion of Hex1 negatively affected germination and hyphal growth, as well as cell wall integrity and resistance to stress conditions. Furthermore, propagation of the fungus in plant tissues, mostly within xylem vessels, is required in subsequent stages of the plant disease, which involves sequential conidiation, germination and hyphal growth cycles [63]. However, we found the Hex1-deficient mutant has a diminished ability to produce conidia, which would probably challenge its ability to efficiently colonize the infected plant [64]. Finally, it is possible that the lack of Hex1 and functional WBs might negatively interfere with the ability of the fungus to withstand the stressful adverse conditions induced in the xylem by the plant's defense mechanisms. For example, one of the host responses to fungal invasion involves rapid bursts of ROS [48]. Since $\Delta$ hex 1 cells are defective in their responses to oxidative stress, this could be an additional factor that compromises its pathogenic potential.

Establishment of viable heterokaryons in fungi, as a result of hyphal fusion and nuclear migration between different individuals, is often prevented in natural populations by incompatibility mechanisms. One of them involves the triggering of a cell death reaction if the fused cells are genetically incompatible, resulting in intense vacuolization, nuclear degradation, cell wall shrinkage and, finally, cell death $[7,33]$. However, this reaction is highly localized and only affects the fused cells, whereas the adjacent hyphal compartments remain unaffected [7]. We hypothesized that the mechanism that is responsible for sealing of the incompatible fused cells to prevent the diffusion of cell death mediators to neighboring cells might involve the WBs, in a function analogous to septal pore plugging upon mechanical damage. However, our time-lapse imaging experiments of incompatible fusions clearly demonstrated that this compartmentalization function is independent of Hex1, as it normally occurs even in $\Delta$ hex 1 hyphae. This is similar to what was previously observed in $N$. crassa [65]. In the course of our experiments, we invariably observed the fusion-induced thickening of septae defining the boundaries of the fused incompatible cells, presumably by intense chitin deposition. This was also detected, at a lesser extent, in the cell wall of these cells, but never affected any of the adjacent hyphal compartments. Similar 
observations have previously been made in Podospora anserina [66]. We propose that the reinforcement of the septae of incompatible cells is involved in their sealing mechanism, which aims at preventing the incompatibility reaction from spreading in the hyphae, and also protecting the neighboring cells once their fused neighbor gets disorganized as the result of the incompatibility reaction.

In conclusion, we demonstrate here important and pleiotropic roles of the protein Hex1 in the plant pathogenic fungus $V$. dahliae. Apart from its function in hyphal compartmentalization in response to hyphal damage, involvement of the protein was identified in fundamental biological processes related to fungal growth, physiology, asexual reproduction, stress response and pathogenicity. Although Hex1 is highly conserved in ascomycetes, diverse functions have been attributed to its homologs in different species, which underlines the necessity of further functional investigations to fully elucidate its multifaceted role in fungal biology.

Author Contributions: Conceived the project, M.A.T. and I.A.P.; designed and performed the experiments, V.V., I.A.P. and E.A.M.; designed and performed the bioinformatic analyses, I.A.P. and V.V.; interpreted and discussed the results, V.V., I.A.P. and M.A.T.; prepared the draft manuscript, V.V. and I.A.P.; discussed and revised the manuscript for submission, I.A.P., M.A.T., V.V. and E.A.M.; provided resources, M.A.T. and M.K. All authors have read and agreed to the submitted version of the manuscript.

Funding: This research is co-financed by Greece and the European Union (European Social Fund- ESF) through the Operational Programme «Human Resources Development, Education and Lifelong Learning» in the context of the project "Strengthening Human Resources Research Potential via Doctorate Research" (MIS-5000432), implemented by the State Scholarships Foundation (IKY).

Acknowledgments: We are grateful to E. K. Ligoxigakis (NAGREF-DEMETER, Heraklion, Greece) for his valuable help with the pathogenicity bioassays. Plasmids pSD1, pOSCAR and pMF357 were generous gifts from Q. B. Nguyen (Kobe University, Japan), S. J. Klosterman (USDA-ARS, Salinas, USA) and E. A. Souza (Federal University of Lavras, Brazil), respectively. Agrobacterium tumefaciens AGL1 was kindly provided by K. Haralampidis (National and Kapodistrian University of Athens, Greece). Plasmids pGKO2 and pFC332 were obtained from Addgene.

Conflicts of Interest: The authors declare no conflict of interest. 


\section{References}

1. Fiddy, C.; Trinci, A.P. Mitosis, septation, branching and the duplication cycle in Aspergillus nidulans. J. Gen. Microbiol. 1976, 97, 169-184, doi:10.1099/00221287-972-169.

2. Stajich, J.E.; Berbee, M.L.; Blackwell, M.; Hibbett, D.S.; James, T.Y.; Spatafora, J.W.; Taylor, J.W. The Fungi. Curr. Biol. 2009, 19, R840-R845, doi:10.1016/j.cub.2009.07.004.

3. Roberson, R.W.; Abril, M.; Blackwell, M.; Letcher, P.; McLaughlin, D.J.; Mouriño-Pérez, R.R.; Riquelme, M.; Uchida, M. Hyphal Structure. In Cellular and Molecular Biology of Filamentous Fungi; John Wiley \& Sons, Ltd, 2014; pp. 8-24.

4. Bartnicki-Garcia, S. Hyphal Tip Growth Outstanding Questions. In Molecular Biology of Fungal Development; Osiewacz, H., Ed.; CRC Press, 2002.

5. Nuss, D.L. Hypovirulence: Mycoviruses at the fungal-plant interface. Nat. Rev. Microbiol. 2005, 3, 632-642, doi:10.1038/nrmicro1206.

6. Diepeningen, A.D. van; Debets, A.J.M.; Slakhorst, S.M.; Hoekstra, R.F. Mitochondrial pAL2-1 plasmid homologs are senescence factors in Podospora anserina independent of intrinsic senescence. Biotechnol. J. 2008, 3, 791-802, doi:10.1002/biot.200800005.

7. Gonçalves, A.P.; Heller, J.; Daskalov, A.; Videira, A.; Glass, N.L. Regulated Forms of Cell Death in Fungi. Front. Microbiol. 2017, 8, doi:10.3389/fmicb.2017.01837.

8. Trinci, A.P.J.; Collinge, A.J. Structure and plugging of septa of wild type and spreading colonial mutants of Neurospora crassa. Arch. Für Mikrobiol. 1973, 91, 355-364, doi:10.1007/BF00425054.

9. Markham, P.; Collinge, A.J. Woronin bodies of filamentous fungi. FEMS Microbiol. Lett. 1987, 46, 1-11, doi:10.1016/0378-1097(87)90182-0.

10. Bleichrodt, R.-J.; van Veluw, G.J.; Recter, B.; Maruyama, J.; Kitamoto, K.; Wösten, H.A.B. Hyphal heterogeneity in Aspergillus oryzae is the result of dynamic closure of septa by Woronin bodies: Hyphal heterogeneity is maintained by septal closure. Mol. Microbiol. 2012, 86, 1334-1344, doi:10.1111/mmi.12077.

11. Liu, F.; Ng, S.K.; Lu, Y.; Low, W.; Lai, J.; Jedd, G. Making two organelles from one: Woronin body biogenesis by peroxisomal protein sorting. J. Cell Biol. 2008, 180, 325339, doi:10.1083/jcb.200705049.

12. Ng, S.K.; Liu, F.; Lai, J.; Low, W.; Jedd, G. A Tether for Woronin Body Inheritance Is Associated with Evolutionary Variation in Organelle Positioning. PLoS Genet. 2009, 5, e1000521, doi:10.1371/journal.pgen.1000521.

13. Beck, J.; Echtenacher, B.; Ebel, F. Woronin bodies, their impact on stress resistance and virulence of the pathogenic mould Aspergillus fumigatus and their anchoring at the septal pore of filamentous Ascomycota. Mol. Microbiol. 2013, 89, 857-871, doi:10.1111/mmi.12316.

14. Lai, J.; Koh, C.H.; Tjota, M.; Pieuchot, L.; Raman, V.; Chandrababu, K.B.; Yang, D.; Wong, L.; Jedd, G. Intrinsically disordered proteins aggregate at fungal cell-to-cell channels and regulate intercellular connectivity. Proc. Natl. Acad. Sci. 2012, 109, 15781-15786, doi:10.1073/pnas.1207467109.

15. Jedd, G.; Chua, N.-H. A new self-assembled peroxisomal vesicle required for efficient resealing of the plasma membrane. Nat. Cell Biol. 2000, 2, 226-231, doi:10.1038/35008652. 
16. Yuan, P.; Jedd, G.; Kumaran, D.; Swaminathan, S.; Shio, H.; Hewitt, D.; Chua, N.-H.; Swaminathan, K. A HEX-1 crystal lattice required for Woronin body function in Neurospora crassa. Nat. Struct. Mol. Biol. 2003, 10, 264-270, doi:10.1038/nsb910.

17. Tenney, K.; Hunt, I.; Sweigard, J.; Pounder, J.I.; McClain, C.; Bowman, E.J.; Bowman, B.J. hex-1, a Gene Unique to Filamentous Fungi, Encodes the Major Protein of the Woronin Body and Functions as a Plug for Septal Pores. Fungal Genet. Biol. 2000, 31, 205-217, doi:10.1006/fgbi.2000.1230.

18. Soundararajan, S.; Jedd, G.; Li, X.; Ramos-Pamploña, M.; Chua, N.H.; Naqvi, N.I. Woronin Body Function in Magnaporthe grisea Is Essential for Efficient Pathogenesis and for Survival during Nitrogen Starvation Stress. Plant Cell 2004, 16, 1564-1574, doi:10.1105/tpc.020677.

19. Curach, N.C.; Te'o, V.S.J.; Gibbs, M.D.; Bergquist, P.L.; Nevalainen, K.M.H. Isolation, characterization and expression of the hex1 gene from Trichoderma reesei. Gene 2004, 331, 133-140, doi:10.1016/j.gene.2004.02.007.

20. Maruyama, J.; Juvvadi, P.R.; Ishi, K.; Kitamoto, K. Three-dimensional image analysis of plugging at the septal pore by Woronin body during hypotonic shock inducing hyphal tip bursting in the filamentous fungus Aspergillus oryzae. Biochem. Biophys. Res. Commun. 2005, 331, 1081-1088, doi:10.1016/j.bbrc.2005.03.233.

21. Beck, J.; Ebel, F. Characterization of the major Woronin body protein HexA of the human pathogenic mold Aspergillus fumigatus. Int. J. Med. Microbiol. 2013, 303, 90-97, doi:10.1016/j.jmm.2012.11.005.

22. Son, M.; Lee, K.-M.; Yu, J.; Kang, M.; Park, J.M.; Kwon, S.-J.; Kim, K.-H. The HEX1 Gene of Fusarium graminearum Is Required for Fungal Asexual Reproduction and Pathogenesis and for Efficient Viral RNA Accumulation of Fusarium graminearum Virus 1. J. Virol. 2013, 87, 10356-10367, doi:10.1128/JVI.01026-13.

23. Kubo, Y.; Fujihara, N.; Harata, K.; Neumann, U.; Robin, G.P.; O'Connell, R. Colletotrichum orbiculare FAM1 Encodes a Novel Woronin Body-Associated Pex22 Peroxin Required for Appressorium-Mediated Plant Infection. mBio 2015, 6, e01305-15, doi:10.1128/mBio.01305-15.

24. Liang, L.; Gao, H.; Li, J.; Liu, L.; Liu, Z.; Zhang, K.-Q. The Woronin body in the nematophagous fungus Arthrobotrys oligospora is essential for trap formation and efficient pathogenesis. Fungal Biol. 2017, 121, 11-20, doi:10.1016/j.funbio.2016.08.010.

25. Yuan, J.; Li, D.; Qin, L.; Shen, J.; Guo, X.; Tumukunde, E.; Li, M.; Wang, S. HexA is required for growth, aflatoxin biosynthesis and virulence in Aspergillus flavus. BMC Mol. Biol. 2019, 20, 4, doi:10.1186/s12867-019-0121-3.

26. Tang, G.; Shang, Y.; Li, S.; Wang, C. MrHex1 is Required for Woronin Body Formation, Fungal Development and Virulence in Metarhizium robertsii. J. Fungi 2020, 6, 172, doi:10.3390/jof6030172.

27. Maruyama, J.; Kitamoto, K. The Woronin Body: A Fungal Organelle Regulating Multicellularity. In Biology of the Fungal Cell; Hoffmeister, D., Gressler, M., Eds.; Springer International Publishing: Cham, 2019; pp. 3-14.

28. Pegg, G.F.; Brady, B.L. Verticillium wilts; CABI Pub.: Wallingford, Oxon, UK, 2002.

29. Klosterman, S.J.; Atallah, Z.K.; Vallad, G.E.; Subbarao, K.V. Diversity, Pathogenicity, and Management of Verticillium Species. Annu. Rev. Phytopathol. 2009, 47, 39-62, doi:10.1146/annurev-phyto-080508-081748.

30. Typas, M.A.; Heale, J.B. Transfer of a Cytoplasmic Factor by Micro-injection in Verticillium. J. Gen. Microbiol. 1979, 111, 375-386, doi:10.1099/00221287-111-2-375. 
31. Typas, M.A. Heterokaryon incompatibility and interspecific hybridization between Verticillium albo-atrum and Verticillium dahliae following protoplast fusion and microinjection. J. Gen. Microbiol. 1983.

32. Typas, M.A.; Heale, J.B. Heterozygous diploid analyses via the parasexual cycle and a cytoplasmic pattern of inheritance in Verticillium spp. Genet. Res. 1978, 31, 131-144, doi:10.1017/S0016672300017894.

33. Paoletti, M. Vegetative incompatibility in fungi: From recognition to cell death, whatever does the trick. Fungal Biol. Rev. 2016, 30, 152-162, doi:10.1016/j.fbr.2016.08.002.

34. Papaioannou, I.A.; Ligoxigakis, E.K.; Vakalounakis, D.J.; Markakis, E.A.; Typas, M.A. Phytopathogenic, morphological, genetic and molecular characterization of a Verticillium dahliae population from Crete, Greece. Eur. J. Plant Pathol. 2013, 136, 577-596, doi:10.1007/s10658-013-0189-4.

35. Papaioannou, I.A.; Dimopoulou, C.D.; Typas, M.A. Structural and phylogenetic analysis of the rDNA intergenic spacer region of Verticillium dahliae. FEMS Microbiol. Lett. 2013, 347, 23-32, doi:10.1111/1574-6968.12215.

36. Holsters, M.; de Waele, D.; Depicker, A.; Messens, E.; van Montagu, M.; Schell, J. Transfection and transformation of Agrobacterium tumefaciens. Mol. Gen. Genet. MGG 1978, 163, 181-187, doi:10.1007/BF00267408.

37. Mullins, E.D.; Chen, X.; Romaine, P.; Raina, R.; Geiser, D.M.; Kang, S. AgrobacteriumMediated Transformation of Fusarium oxysporum: An Efficient Tool for Insertional Mutagenesis and Gene Transfer. Phytopathology 2001, 91, 173-180, doi:10.1094/PHYTO.2001.91.2.173.

38. Markakis, E.A.; Ligoxigakis, E.K.; Avramidou, E.V.; Tzanidakis, N. Survival, Persistence, and Infection Efficiency of Verticillium dahliae Passed Through the Digestive System of Sheep. Plant Dis. 2014, 98, 1235-1240, doi:10.1094/PDIS-12-13-1201-RE.

39. Markakis, E.A.; Fountoulakis, M.S.; Daskalakis, G.Ch.; Kokkinis, M.; Ligoxigakis, E.K. The suppressive effect of compost amendments on Fusarium oxysporum f.sp. radiciscucumerinum in cucumber and Verticillium dahliae in eggplant. Crop Prot. 2016, 79, 70 79, doi:10.1016/j.cropro.2015.10.015.

40. Papaioannou, I.A.; Typas, M.A. High-Throughput Assessment and Genetic Investigation of Vegetative Compatibility in Verticillium dahliae. J. Phytopathol. 2015, 163, 475-485, doi:10.1111/jph.12345.

41. Schindelin, J.; Arganda-Carreras, I.; Frise, E.; Kaynig, V.; Longair, M.; Pietzsch, T.; Preibisch, S.; Rueden, C.; Saalfeld, S.; Schmid, B.; et al. Fiji: an open-source platform for biological-image analysis. Nat. Methods 2012, 9, 676-682, doi:10.1038/nmeth.2019.

42. Kumar, S.; Stecher, G.; Li, M.; Knyaz, C.; Tamura, K. MEGA X: Molecular Evolutionary Genetics Analysis across Computing Platforms. Mol. Biol. Evol. 2018, 35, 1547-1549, doi:10.1093/molbev/msy096.

43. Buchan, D.W.A.; Jones, D.T. The PSIPRED Protein Analysis Workbench: 20 years on. Nucleic Acids Res. 2019, 47, W402-W407, doi:10.1093/nar/gkz297.

44. Zimmermann, L.; Stephens, A.; Nam, S.-Z.; Rau, D.; Kübler, J.; Lozajic, M.; Gabler, F.; Söding, J.; Lupas, A.N.; Alva, V. A Completely Reimplemented MPI Bioinformatics Toolkit with a New HHpred Server at its Core. J. Mol. Biol. 2018, 430, 2237-2243, doi:10.1016/j.jmb.2017.12.007.

45. Webb, B.; Sali, A. Comparative Protein Structure Modeling Using MODELLER. Curr. Protoc. Protein Sci. 2016, 86, 2.9.1-2.9.37, doi:10.1002/cpps.20. 
46. Inderbitzin, P.; Davis, R.M.; Bostock, R.M.; Subbarao, K.V. The Ascomycete Verticillium longisporum Is a Hybrid and a Plant Pathogen with an Expanded Host Range. PLOS ONE 2011, 6, e18260, doi:10.1371/journal.pone.0018260.

47. Gould, S.J.; Keller, G.A.; Hosken, N.; Wilkinson, J.; Subramani, S. A conserved tripeptide sorts proteins to peroxisomes. J. Cell Biol. 1989, 108, 1657-1664, doi:10.1083/jcb.108.5.1657.

48. Lamb, C.; Dixon, R.A. The Oxidative Burst in Plant Disease Resistance. Annu. Rev. Plant Physiol. Plant Mol. Biol. 1997, 48, 251-275, doi:10.1146/annurev.arplant.48.1.251.

49. Di Pietro, A.; Talbot, N.J. Fungal pathogenesis: Combatting the oxidative burst. Nat. Microbiol. 2017, 2, 1-2, doi:10.1038/nmicrobiol.2017.95.

50. Corral-Ramos, C.; Roca, M.G.; Di Pietro, A.; Roncero, M.I.G.; Ruiz-Roldán, C. Autophagy contributes to regulation of nuclear dynamics during vegetative growth and hyphal fusion in Fusarium oxysporum. Autophagy 2015, 11, 131-144, doi:10.4161/15548627.2014.994413.

51. Knoll, A.H. The Multiple Origins of Complex Multicellularity. Annu. Rev. Earth Planet. Sci. 2011, 39, 217-239, doi:10.1146/annurev.earth.031208.100209.

52. Michael J. Carlile,; Sarah C. Watkinson; Graham W. Gooday The Fungi; 2nd ed.; academic Press: London, 2001.

53. Simonin, A.; Palma-Guerrero, J.; Fricker, M.; Glass, N.L. Physiological Significance of Network Organization in Fungi. Eukaryot. Cell 2012, 11, 1345-1352, doi:10.1128/EC.00213-12.

54. Schmieder, S.S.; Stanley, C.E.; Rzepiela, A.; van Swaay, D.; Sabotič, J.; Nørrelykke, S.F.; deMello, A.J.; Aebi, M.; Künzler, M. Bidirectional Propagation of Signals and Nutrients in Fungal Networks via Specialized Hyphae. Curr. Biol. 2019, 29, 217-228.e4, doi:10.1016/j.cub.2018.11.058.

55. Steinberg, G.; Harmer, N.J.; Schuster, M.; Kilaru, S. Woronin body-based sealing of septal pores. Fungal Genet. Biol. 2017, 109, 53-55, doi:10.1016/j.fgb.2017.10.006.

56. Jin, L.; Li, G.; Yu, D.; Huang, W.; Cheng, C.; Liao, S.; Wu, Q.; Zhang, Y. Transcriptome analysis reveals the complexity of alternative splicing regulation in the fungus Verticillium dahliae. BMC Genomics 2017, 18, doi:10.1186/s12864-017-3507-y.

57. Tey, W.K.; North, A.J.; Reyes, J.L.; Lu, Y.F.; Jedd, G. Polarized Gene Expression Determines Woronin Body Formation at the Leading Edge of the Fungal Colony. Mol. Biol. Cell 2005, 16, 9.

58. Momany, M.; Richardson, E.A.; Sickle, C.V.; Jedd, G. Mapping Woronin Body Position in Aspergillus nidulans. Mycologia 2002, 94, 260, doi:10.2307/3761802.

59. Riquelme, M.; Bredeweg, E.L.; Callejas-Negrete, O.; Roberson, R.W.; Ludwig, S.; Beltrán-Aguilar, A.; Seiler, S.; Novick, P.; Freitag, M. The Neurospora crassa exocyst complex tethers Spitzenkörper vesicles to the apical plasma membrane during polarized growth. Mol. Biol. Cell 2014, 25, 1312-1326, doi:10.1091/mbc.E13-06-0299.

60. Heller, J.; Tudzynski, P. Reactive oxygen species in phytopathogenic fungi: signaling, development, and disease. Annu. Rev. Phytopathol. 2011, 49, 369-390, doi:10.1146/annurev-phyto-072910-095355.

61. Kim, K.-H.; Willger, S.D.; Park, S.-W.; Puttikamonkul, S.; Grahl, N.; Cho, Y.; Mukhopadhyay, B.; Cramer, R.A.; Lawrence, C.B. TmpL, a Transmembrane Protein Required for Intracellular Redox Homeostasis and Virulence in a Plant and an Animal Fungal Pathogen. PLoS Pathog. 2009, 5, e1000653, doi:10.1371/journal.ppat.1000653. 
62. Qi, X.; Li, X.; Guo, H.; Guo, N.; Cheng, H. VdPLP, A Patatin-Like Phospholipase in Verticillium dahliae, Is Involved in Cell Wall Integrity and Required for Pathogenicity. Genes 2018, 9, doi:10.3390/genes9030162.

63. Fradin, E.F.; Thomma, B.P.H.J. Physiology and molecular aspects of Verticillium wilt diseases caused by $V$. dahliae and V. albo-atrum. Mol. Plant Pathol. 2006, 7, 71-86, doi:10.1111/j.1364-3703.2006.00323.x.

64. Luo, X.; Mao, H.; Wei, Y.; Cai, J.; Xie, C.; Sui, A.; Yang, X.; Dong, J. The fungal-specific transcription factor Vdpf influences conidia production, melanized microsclerotia formation and pathogenicity in Verticillium dahliae. Mol. Plant Pathol. 2016, 17, 13641381, doi:10.1111/mpp.12367.

65. Hutchison, E.; Brown, S.; Tian, C.; Glass, N.L. Transcriptional profiling and functional analysis of heterokaryon incompatibility in Neurospora crassa reveals that reactive oxygen species, but not metacaspases, are associated with programmed cell death. Microbiol. Read. Engl. 2009, 155, 3957-3970, doi:10.1099/mic.0.032284-0.

66. Dementhon, K.; Paoletti, M.; Pinan-Lucarré, B.; Loubradou-Bourges, N.; Sabourin, M.; Saupe, S.J.; Clavé, C. Rapamycin Mimics the Incompatibility Reaction in the Fungus Podospora anserina. Eukaryot. Cell 2003, 2, 238-246, doi:10.1128/EC.2.2.238246.2003. 


\section{Supplementary Figures}

Hex1, the Major Component of Woronin Bodies, is Required for Normal Development, Pathogenicity and Stress Response in the Plant Pathogenic Fungus Verticillium dahliae

Vasileios Vangalis ${ }^{1}$, Ioannis A. Papaioannou ${ }^{2}$, Emmanouil A. Markakis ${ }^{3}$, Michael Knop $^{2,4}$, Milton A. Typas ${ }^{1, *}$

1 Department of Genetics \& Biotechnology, Faculty of Biology, National and Kapodistrian University of Athens, Greece

2 Zentrum für Molekulare Biologie der Universität Heidelberg (ZMBH), DKFZ-ZMBH Alliance, Heidelberg, Germany

3 Laboratory of Mycology, Department of Viticulture, Vegetable Crops, Floriculture and Plant Protection, Institute of Olive Tree, Subtropical Crops and Viticulture, N.AG.RE.F., Hellenic Agricultural Organization - DEMETER, Heraklion, Crete, Greece

4 Cell Morphogenesis and Signal Transduction Group, DKFZ, DKFZ-ZMBH Alliance, Heidelberg, Germany

* To whom correspondence should be addressed: matypas@biol.uoa.gr 
bioRxiv preprint doi: https://doi.org/10.1101/2020.11 04.367870; this version posted November 4, 2020. The copyright holder for this preprint (which was not certified by peer review) is the author/funder, who has granted bioRxiv a license to display the preprint in perpetuity. It is made available under aCC-BY-NC-ND 4.0 International license.

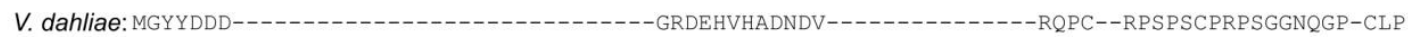

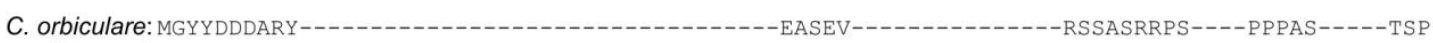

T. reesei: MGYYDDEGSYHSLKHGVAKTI DKLLPHHHHHHHHSDHHHHSDHHDHNNTT ITEHVEVDVVRHDANHSR--RAAPA--------TE-SQP

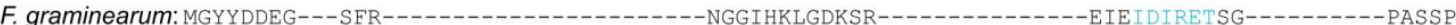

N. crassa: MGYYDDD----------

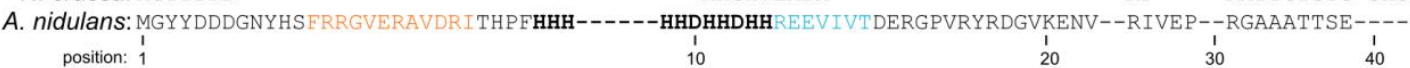

$\beta 1 \mathrm{H}$

$\beta 2$

$\beta 3$

$\beta 4$

$\beta 5$

$\beta 6$

$\beta 7$

$\beta 8$

V. dahliae: NTVSIPCNHIRMGDFLMLQGRPCQVIRISISAATGQYRYLGVDLFTKQLHEESSYISNPEPSVVVQTMLGPVFKQYRVLDMHDGRIVAMT

C. orbiculare: NTVTIPCHHIRLGDFLMLQGRPCQVIKISTSAATGQYRYLGVDLFTKQLHEESSFISNPAPSVVVQTMLGPVFKQYRVLDLADGHVVAMT T. reesei: QTVSI PCHHIRLGDFLMLQGRPCQVIRISTSSATGQYRYLGVDLFTKQLHEESSFISNPAPSVVVQTMLGPVFKQYRVLDMADGYVTAMT F. graminearum: NTVS I PCHH IRLGDFLMLQGRPCQVIRISTSSATGQYRYLGVDLFTKQLHEESSFISNPAPSVVVQSMLGPVFKQYRVLDMQEGQIVAMT

N. crassa: QTVTI PCHHIRLGDILILQGRPCQVIRISTSAATGQHRYLGVDLFTKQLHEESSFVSNPAPSVVVQTMLGPVFKQYRVLDMQDGS IVAMT

A. nidulans: -TVPIPTHFIRVGDI LVLQGRPCQVIRISSSPMTDQRRYTGVDLFTRELHEESSFVSNPKPSVVVQTMLGPVYKTYRI LDIQEGTIVALT $\begin{array}{cccccccccc}\text { position: } & 1 & 1 & 1 & 1 & 1 & 1 & 1 & 1 & 1 \\ & 50 & 60 & 70 & 80 & 90 & 100 & 110 & 120 & 130\end{array}$

$\begin{array}{llll}\mathrm{H} 2 & \mathrm{H} 2 & \beta 11\end{array}$

V. dahliae: ETGDVKPDLPVIDQSNLWSRLNTAFECGRGSVRVLVLNDRGRELAVDMKTIHGSRL

C. orbiculare: ETGDVKQGLPVIDQSNLWTRLNSAFDSGRGSVRVLVLNDAGRELAVDVKVIHGSRI

T. reesei: ETGDVKOGLKVIDOSNLWSRLOQAFESGRGSVRVLVLNDGGHELAVEMKVVHGSRI

F. graminearum: ETGDVKQGLPVIDQSNLYSRLHNAFESGRGSVRVLVLNDGGRELAVDMKVI HGSRI

N. crassa: ETGDVKQNLPVIDQS LWNRLQKAFESGRGSVRVLVVSDHGREMAVDMKVVHGSRL

A. nidulans: ESGDVKSGIPVI PQGNLYQRIKDAFLEGRGSVRALVINDGGRELVVDYKIIHSSRI

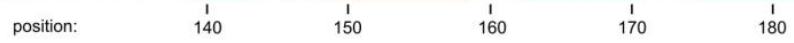

Figure S1. Multiple sequence alignment of Hex1 homologs of $V$. dahliae and other selected ascomycetes, for comparison. Secondary structure elements (predicted by PSIPRED) have been highlighted in blue (beta-sheets) or orange (helices). An asterisk above the alignment indicates the position of a conserved histidine residue required for Hex1 crystal formation in $N$. crassa (at position 51 in $V$. dahliae). The peroxisome targeting signal (SRL tripeptide) at the C-terminus of the sequences is shown in red letters. Bold black letters are used for the predicted poly-histidine motif in some sequences. 
A

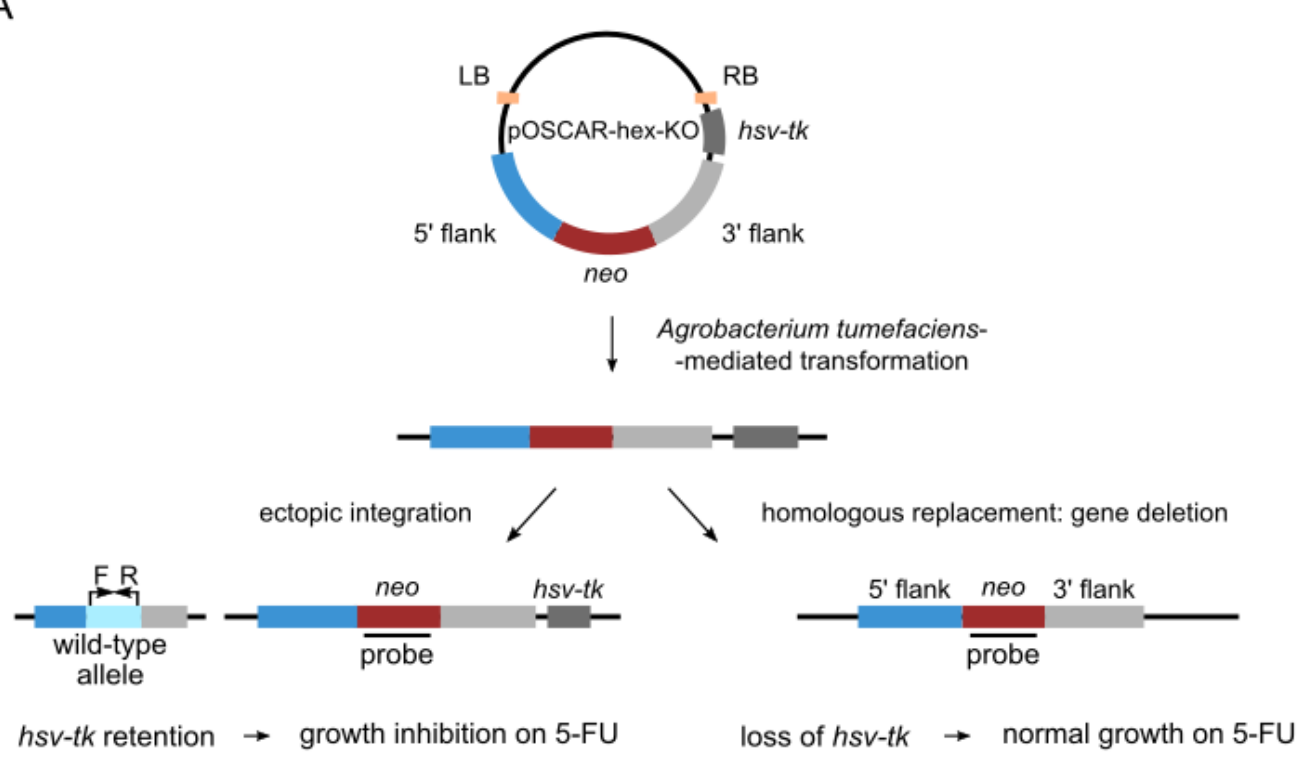

F, R: primers used for PCR screening

B

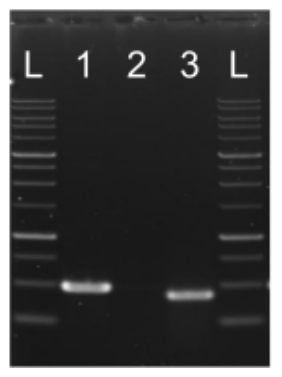

C

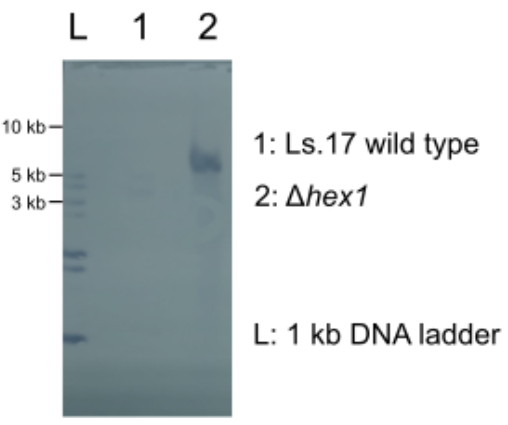

Figure S2. Schematic representation of the strategy followed for hex1 deletion in $V$. dahliae. (A) A binary vector for Agrobacterium tumefaciens-mediated transformation of $V$. dahliae was constructed by combining the neo cassette (conferring resistance to geneticin), flanked by 2 $\mathrm{kb}$-long genomic sequences, with the $h s v$-tk thymidine kinase cassette for selection against ectopic transformants, in the backbone of plasmid pOSCAR. The hsv-tk cassette, which leads to growth inhibition on 5-FU-amended media, is expected to be randomly integrated into the fungal genome and expressed in the majority of ectopic events, but lost in the case of double homologous recombination and gene deletion. (B) PCR validation of hex1 deletion using the hex1-specific primer pair Vdhex1F/R (shown as $F$ and $R$ in panel $A$, respectively). Primers $\mathrm{ctrlF/R}$ were used in control reactions for assessing the quality of the template. (C) Southern blot of the wild-type isolate and the hex1 deletion mutant using a probe for the neo cassette (as shown in panel A). 
bioRxiv preprint doi: https://doi org/10.1101/2020.11 04 367870; this version posted November 4,2020 . The copyright holder for this preprint (which was not certified by peer review) is the author/funder, who has granted bioRxiv a license to display the preprint in perpetuity. It is made available under aCC-BY-NC-ND 4.0 International license.

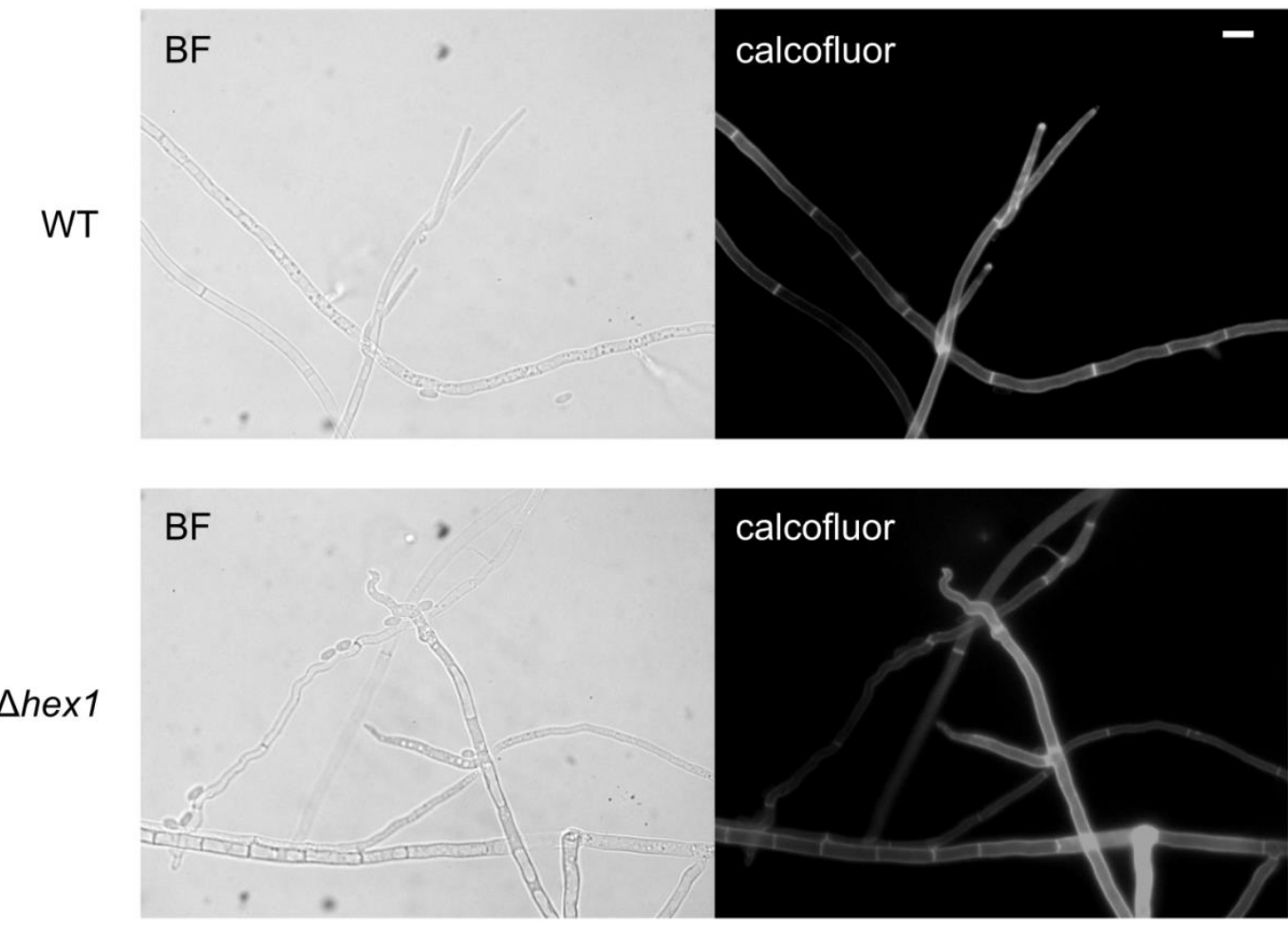

Figure S3. Morphological characteristics of hyphae of the wild-type and the $\Delta h e x 1$ strains. The mutant hyphae and conidiophores, but not the wild-type ones, often exhibited a "curly" phenotype at their apical regions. Cell wall-staining was performed using calcofluor white M2R. Bar $=10 \mu \mathrm{m}$. 
A

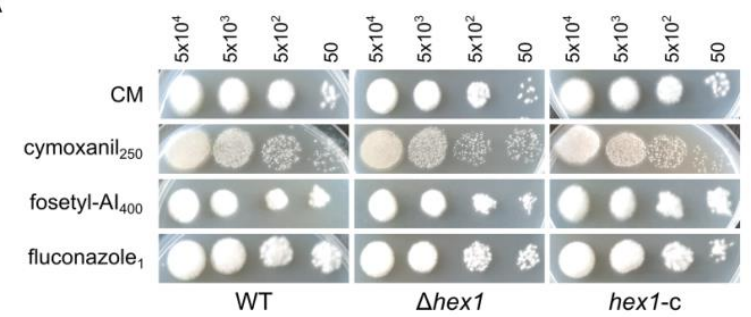

B

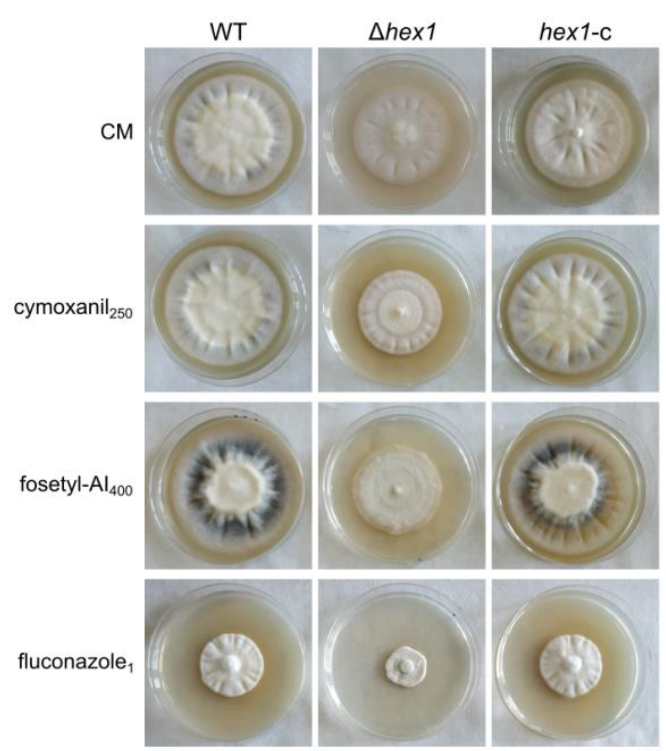

Figure S4. Effects of antifungal agents on $\Delta$ hex1. (A) Responses of the wild-type, the deletion ( $\Delta$ hex1) and the complemented (hex1-c) strains to cymoxanil, fosetyl-Al, mandipropamid, cyflufenamid and fluconazole as regards germination (top; the number of inoculated conidia per spot are provided above the images; growth for 3 days) and radial growth (right; growth for 18 days). (B) Relative growth inhibition by the same substances (each condition was tested in triplicate; bars = SD; statistical testing by one-way ANOVA followed by Tukey's post-hoc test ( $p \leq 0.05$ ). All concentrations are given in $\mu \mathrm{g} / \mathrm{mL}$. 
bioRxiv preprint doi: https://doi.org/10.1101/2020.11.04.367870; this version posted November 4, 2020. The copyright holder for this preprint (which was not certified by peer review) is the author/funder, who has granted bioRxiv a license to display the preprint in perpetuity. It is made available under aCC-BY-NC-ND 4.0 International license.

A
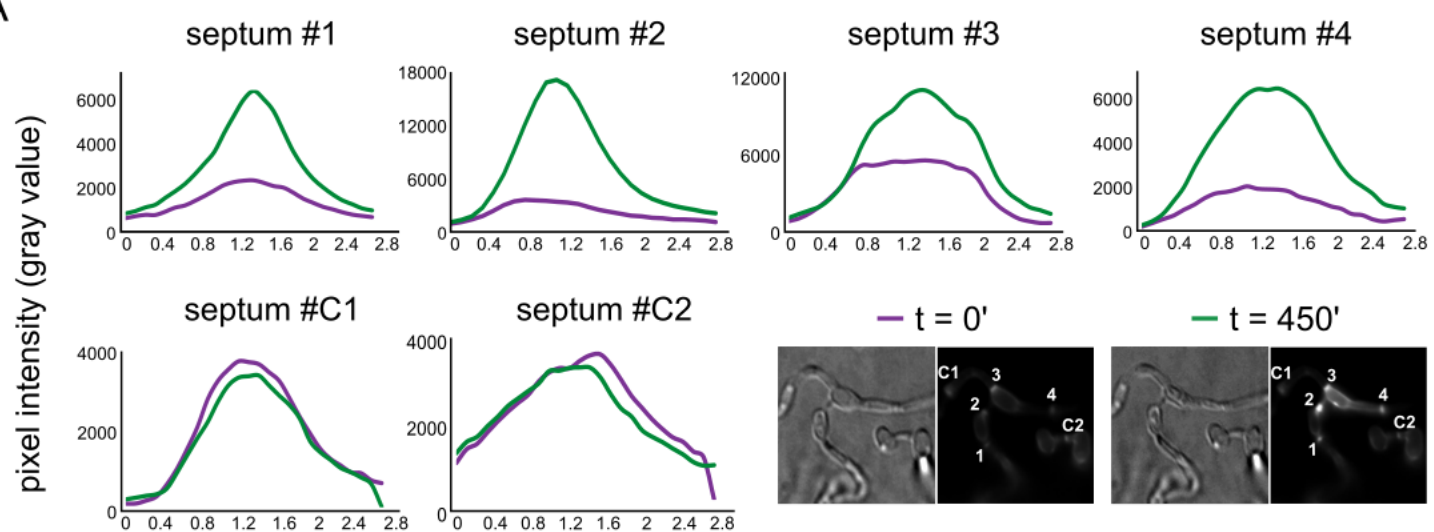

distance $(\mu \mathrm{m})$
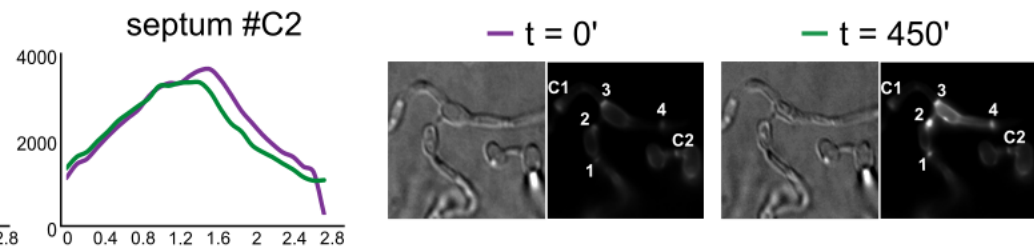

$\mathrm{B}$
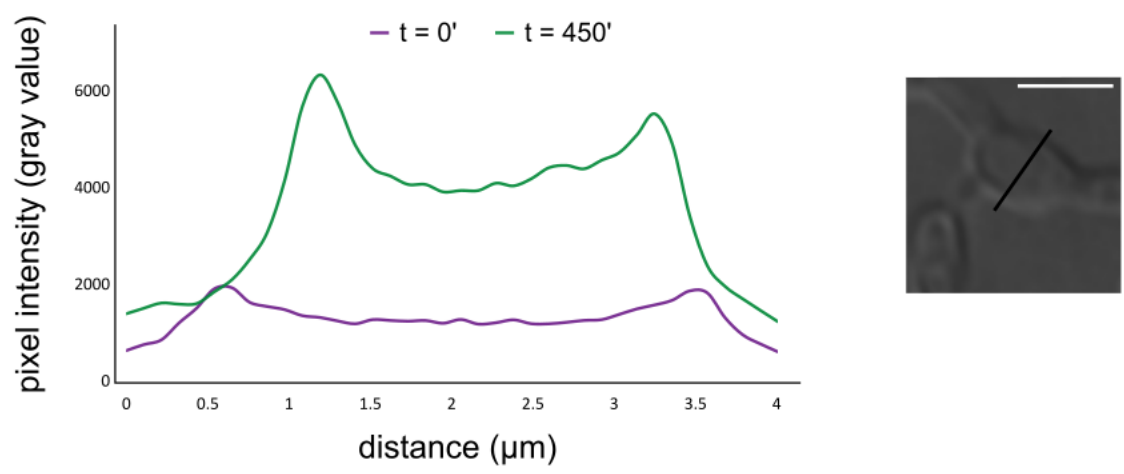

Figure S5. Vdhex 1 is not involved in heterokaryon incompatibility. (A) Quantification of blue fluorescence intensity (calcofluor white M2R staining of cell wall chitin) along the four septae that surround the incompatible fused cell shown in Figure 7A; two septae from neighboring regions of the adjacent hyphae (C1-C2) are also included for comparison. Intensity quantification is shown for two time points, before and after the visible effects of the incompatibility reaction, respectively. See also Figure 7. (B) Similar to panel A, for the crosssection of the fused cell shown in the magnified region of interest on the right.

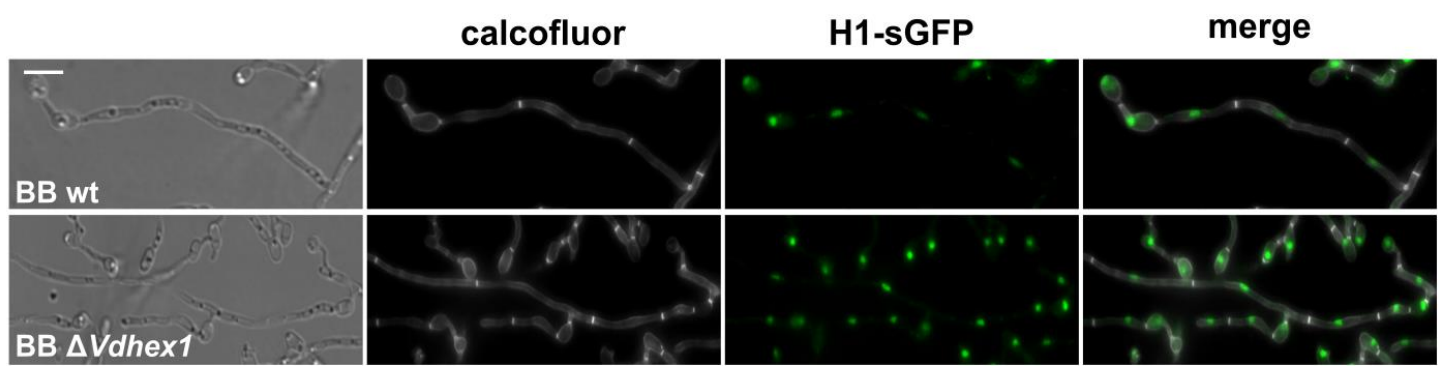

Figure S6. Nuclear copy number per hyphal compartment in mycelia of the $V$. dahliae BB wild-type and $\Delta$ hex 1 strains with histone $\mathrm{H} 1$-tagging with sGFP for nuclear labeling. Cell wall staining was performed using calcofluor white M2R. Bar $=10 \mu \mathrm{m}$. 
Table S1: Verticillium dahliae strains constructed and used in this study.

\begin{tabular}{|c|c|c|c|}
\hline strain & $\begin{array}{l}\text { derived from } \\
\text { wild-type isolate }\end{array}$ & engineered genotype & constructed with plasmid(s) \\
\hline Ls.17 & - & wild type & - \\
\hline Ls.17-hex1-gfp & Ls.17 & hex1-sgfp, hph & pOSCAR-hex-GFP \\
\hline Ls.17- $\Delta$ hex1 & Ls. 17 & $\Delta$ hex1::neo & pOSCAR-hex-KO \\
\hline Ls.17- $\Delta$ hex 1.1 & Ls.17 & $\Delta$ hex1::neo, nit1 & pOSCAR-hex-KO \\
\hline Ls.17- $\Delta$ hex1.M & Ls.17 & $\Delta$ hex1::neo, nitM & pOSCAR-hex-KO \\
\hline Ls.17-hex1-c & Ls.17 & $\Delta h e x 1:: n e o, h e x 1, h p h$ & $\begin{array}{l}\text { pOSCAR-hex-KO, Vdhex } 1 \text { and } \\
\text { pUCATPH }\end{array}$ \\
\hline Ls.17-gfp & Ls. 17 & sgfp, neo & pBS-GFP-gen \\
\hline BB- $\Delta$ hex1-h1-g & BB & $\Delta h e x 1:: n e o$, Nch1-sgfp, hph & pOSCAR-hex-KO and pMF357 \\
\hline BB-h1-g & BB & Nch1-sgfp, hph & pMF357 \\
\hline T9.M & T9 & nitM & - \\
\hline V607I.M & V607I & nitM & - \\
\hline PH.M & $\mathrm{PH}$ & nitM & - \\
\hline Ls.17.M & Ls. 17 & nitM & - \\
\hline V16.M & V16 & nitM & - \\
\hline V702I.M & V702I & nitM & - \\
\hline CA26.M & CA26 & nitM & - \\
\hline 530-1.M & $530-1$ & nitM & - \\
\hline 25V.M & $25 \mathrm{~V}$ & nitM & - \\
\hline 70-21.M & $70-21$ & nitM & - \\
\hline Dvd-E6.M & Dvd-E6 & nitM & - \\
\hline S39.M & S39 & nitM & - \\
\hline Ca.146.M & Ca.146 & nitM & - \\
\hline Cf.162.M & Cf.162 & nitM & - \\
\hline V44.1 & V44 & nit1 & - \\
\hline V661I.1 & V661I & nit1 & - \\
\hline V320I.1 & V320I & nit1 & - \\
\hline Ls.17.1 & Ls. 17 & nit1 & - \\
\hline Cf.38.1 & Cf.38 & nit1 & - \\
\hline V702I.1 & V702I & nit1 & - \\
\hline $530-1.1$ & $530-1$ & nit1 & - \\
\hline $25 \mathrm{~V} .1$ & $25 \mathrm{~V}$ & nit1 & - \\
\hline PCW.1 & PCW & nit1 & - \\
\hline BB.1 & $\mathrm{BB}$ & nit1 & - \\
\hline V684.1 & V684I & nit1 & - \\
\hline Ca.148.1 & Ca.148 & nit1 & - \\
\hline V13.1 & V13 & nit1 & - \\
\hline
\end{tabular}


Table S2: List of DNA oligonucleotides used in this study.

\begin{tabular}{|c|c|c|c|}
\hline oligo name & sequence $\left(5^{\prime}\right.$ to $\left.3^{\prime}\right)$ & $\begin{array}{l}\text { template } \\
\text { (strain or plasmid) }\end{array}$ & $\begin{array}{l}\text { used for } \\
\text { construction/ } \\
\text { validation of } \\
\text { strain or plasmid }\end{array}$ \\
\hline $\begin{array}{l}\text { 5flnhexF } \\
\text { 5flnhexR }\end{array}$ & $\begin{array}{l}\text { GAAACGACAATCTGATCCAAGCTCAAGC } \\
\text { TATTCACAAGCAAGAAAGAGCC } \\
\text { CAATATCAGTTAACGTCGGGGGAGGATA } \\
\text { TAGGGAC }\end{array}$ & Ls.17 & \\
\hline $\begin{array}{l}\text { genhexF } \\
\text { genhexR }\end{array}$ & $\begin{array}{l}\text { CTATATCCTCCCCCGACGTTAACTGATAT } \\
\text { TGAAGGAGCAC } \\
\text { AATTACAGACATGTACAAACCCAGGGCT } \\
\text { GGTGACGG }\end{array}$ & pSD1 & pOSCAR-hex-KO \\
\hline $\begin{array}{l}\text { 3flnhexF } \\
\text { 3flnhexR }\end{array}$ & $\begin{array}{l}\text { CACCAGCCCTGGGTTTGTACATGTCTGT } \\
\text { AATTGAC } \\
\text { GCCTGCAGGTCGCGAGCGATCGCGGTA } \\
\text { CCTCATGCCAGGCTGCCCA }\end{array}$ & Ls.17 & \\
\hline $\begin{array}{l}\text { hsv-oscar-slic-f } \\
\text { hsv-oscar-slic-r }\end{array}$ & $\begin{array}{l}\text { GTTAATTACCCTGTTATCCCTATTATGTA } \\
\text { AAACGACGGCCAGT } \\
\text { CCTCTCTTAAGGTAGCGAGCTCTTACAG } \\
\text { GAAACAGCTATGAC }\end{array}$ & pGKO2 & \\
\hline $\begin{array}{l}\text { VdhexF } \\
\text { VdhexR } \\
\text { ctrlF } \\
\text { ctrlR }\end{array}$ & $\begin{array}{l}\text { ACCGACTCGTCCACCCTAAAG } \\
\text { AGCCACGGCCACACTCG } \\
\text { GCGCAGTAGGCCAGATCAGG } \\
\text { GTCCCGTGCTCGTTTGGTG }\end{array}$ & $\begin{array}{l}\text { Ls.17, } \\
\text { Ls.17- } \Delta \text { hex1, } \\
\text { Ls.17-hex1-c } \\
\text { Ls.17- } \Delta \text { hex1 }\end{array}$ & $\begin{array}{l}\text { Ls.17- } \Delta \text { hex1, } \\
\text { Ls.17-hex1-c }\end{array}$ \\
\hline $\begin{array}{l}5 f \operatorname{lnhexF} \\
\text { 3flnhexR }\end{array}$ & $\begin{array}{l}\text { GAAACGACAATCTGATCCAAGCTCAAGC } \\
\text { TATTCACAAGCAAGAAAGAGCC } \\
\text { GCCTGCAGGTCGCGAGCGATCGCGGTA } \\
\text { CCTCATGCCAGGCTGCCCA }\end{array}$ & Ls.17 & Ls.17-hex1-c \\
\hline $\begin{array}{l}\text { 5flnhexF } \\
\text { hex-gfp-R }\end{array}$ & $\begin{array}{l}\text { GAAACGACAATCTGATCCAAGCTCAAGC } \\
\text { TATTCACAAGCAAGAAAGAGCC } \\
\text { GCCCTTGCTCACCATCTGCCTAACACCA } \\
\text { GAGACAC }\end{array}$ & Ls. 17 & \\
\hline $\begin{array}{l}\text { gfp-hex-F } \\
\text { tef-gfp-R }\end{array}$ & $\begin{array}{l}\text { AAATCGAATGTCCGCTTAGTCGAGCTTG } \\
\text { TACAGCTCG } \\
\text { GTACAAGCTCGACTAAGCGGACATTCGA } \\
\text { TTTATGC }\end{array}$ & pIGAPA & 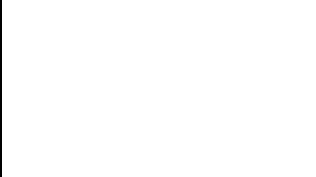 \\
\hline $\begin{array}{l}\text { hyg-tef-F } \\
\text { hyg-hex-R }\end{array}$ & $\begin{array}{l}\text { CAATATCAGTTAACGTCGTATTGGGATG } \\
\text { AATTTTGTATGC } \\
\text { CAATTACAGACATGTACATTGTGTCGCC } \\
\text { CTTATTCGAC }\end{array}$ & pFC332 & pOSCAR-hex-GFP \\
\hline $\begin{array}{l}\text { 3flhex-hygF } \\
\text { 3flnhexR }\end{array}$ & $\begin{array}{l}\text { GAATAAGGGCGACACAATGTACATGTCT } \\
\text { GTAATTGAC } \\
\text { GCCTGCAGGTCGCGAGCGATCGCGGTA } \\
\text { CCTCATGCCAGGCTGCCCA }\end{array}$ & Ls. 17 & \\
\hline
\end{tabular}


Table S3: List of plasmids constructed and used in this study.

\begin{tabular}{|c|c|c|c|}
\hline plasmid & backbone & description & source (Addgene ID) \\
\hline \multicolumn{4}{|c|}{ plasmids used for recombinant vector construction } \\
\hline pIGPAPA & - & $\mathrm{P}_{\text {icr }} s g f p-\mathrm{T}_{\text {nosl }}, h p h$ & [1] \\
\hline pUCATPH & - & hph & [2] \\
\hline pSD1 & pBluescript II & $\mathrm{P}_{\text {gpda }}, \mathrm{P}_{t r p c}$, neo & [3] \\
\hline pBS-genR & pBluescript II & neo & This study \\
\hline pFC332 & - & AMA1, hph, $\mathrm{P}_{\text {tef1 }}-$ SpCas9-Ttef1 & [4] (\# 87845) \\
\hline pOSCAR & pPZP-RCS2 & A. tumefaciens binary vector & [5] \\
\hline pGKO2 & $\mathrm{pDHt}-\mathrm{KS}$ & $h s v-t k$ & [6] (\# 63617) \\
\hline \multicolumn{4}{|c|}{ plasmid used for fluorescent labeling } \\
\hline pMF357 & - & $\mathrm{P}_{c c g 1}-\mathrm{NcH1}$-sgfp, hph & [7] \\
\hline pBS-GFP-gen & pBS-genR & $\mathrm{P}_{i c \Gamma}$ sgfp- $\mathrm{T}_{\text {nosl }}$, neo & This study \\
\hline \multicolumn{4}{|c|}{ plasmids used for deletion and tagging of Vdhex1 } \\
\hline pOSCAR-hex-KO & pOSCAR & $\begin{array}{c}\text { 5' } \mathrm{H}_{\text {hex }}-\text {-neo-3' } \mathrm{H}_{\text {hex } 1}, \text { hsv-tk } \\
(\mathrm{H}: 2.0 \mathrm{~kb} \text {-long homology arms) }\end{array}$ & This study \\
\hline pOSCAR-hex-GFP & pOSCAR & $\begin{array}{c}5{ }^{\prime} \mathrm{H}_{\text {hext }}-\text { hex } 1 \text {-sgfp- } \mathrm{T}_{\text {tef1 }}, \text { hph } \\
(\mathrm{H}: 2.0 \mathrm{~kb}-\text { long homology arms })\end{array}$ & This study \\
\hline
\end{tabular}

\section{References}

1. Horwitz, B.A.; Sharon, A.; Lu, S.-W.; Ritter, V.; Sandrock, T.M.; Yoder, O.C.; Turgeon, B.G. A G Protein Alpha Subunit from Cochliobolus heterostrophus Involved in Mating and Appressorium Formation. Fungal Genet. Biol. 1999, 26, 19-32, doi:10.1006/fgbi.1998.1094.

2. Lu, S.; Lyngholm, L.; Yang, G.; Bronson, C.; Yoder, O.C.; Turgeon, B.G. Tagged mutations at the Tox1 locus of Cochliobolus heterostrophus by restriction enzyme-mediated integration. Proc. Natl. Acad. Sci. U. S. A. 1994, 91, 12649-12653, doi:10.1073/pnas.91.26.12649.

3. Nguyen, Q.B.; Kadotani, N.; Kasahara, S.; Tosa, Y.; Mayama, S.; Nakayashiki, H. Systematic functional analysis of calcium-signalling proteins in the genome of the rice-blast fungus, Magnaporthe oryzae, using a high-throughput RNA-silencing system. Mol. Microbiol. 2008, 68, 1348-1365, doi:10.1111/j.1365-2958.2008.06242.x.

4. Nødvig, C.S.; Nielsen, J.B.; Kogle, M.E.; Mortensen, U.H. A CRISPR-Cas9 System for Genetic Engineering of Filamentous Fungi. PLOS ONE 2015, 10, e0133085, doi:10.1371/journal.pone.0133085.

5. Paz, Z.; García-Pedrajas, M.D.; Andrews, D.L.; Klosterman, S.J.; Baeza-Montañez, L.; Gold, S.E. One Step Construction of Agrobacterium-Recombination-ready-plasmids (OSCAR), an efficient and robust tool for ATMT based gene deletion construction in fungi. Fungal Genet. Biol. 2011, 48, 677-684, doi:10.1016/j.fgb.2011.02.003.

6. Khang, C.H.; Park, S.-Y.; Lee, Y.-H.; Kang, S. A dual selection based, targeted gene replacement tool for Magnaporthe grisea and Fusarium oxysporum. Fungal Genet. Biol. FG B 2005, 42, 483-492, doi:10.1016/j.fgb.2005.03.004.

7. Ishikawa, F.H.; Souza, E.A.; Shoji, J.; Connolly, L.; Freitag, M.; Read, N.D.; Roca, M.G. Heterokaryon Incompatibility Is Suppressed Following Conidial Anastomosis Tube Fusion in a Fungal Plant Pathogen. PLoS ONE 2012, 7, e31175, doi:10.1371/journal.pone.0031175. 
Table S4: Results from the heterokaryon compatibility tests between nit mutants of $V$. dahliae isolates.

\begin{tabular}{|c|c|c|c|c|c|}
\hline & & & V. dahliae & .17 (VCG 2B & \\
\hline & & nit1 & $\Delta$ hex1 nit1 & nitM & $\Delta h e x 1$ nitM \\
\hline VCG 2B & Ls.17- $\Delta$ hex1.1 & & & + & + \\
\hline VCG 2B & Ls.17- $\Delta$ hex1.M & + & + & & \\
\hline VCG $1 \mathrm{~A}$ & V44.1 & & & $+/-$ & - \\
\hline VCG $1 \mathrm{~A}$ & T9.M & $+/-$ & $+/-$ & & \\
\hline VCG 1B & V661I.1 & & & - & - \\
\hline VCG 1B & V607I.M & - & - & & \\
\hline VCG $2 A$ & V320I.1 & & & - & - \\
\hline VCG $2 A$ & PH.M & - & - & & \\
\hline VCG 2B & Ls.17.1 & & & + & + \\
\hline VCG 2B & Cf.38.1 & & & + & + \\
\hline VCG 2B & Ls.17.M & + & + & & \\
\hline VCG 2B & V16.M & + & + & & \\
\hline VCG $2 \mathrm{Ba}$ & V702I.1 & & & $+/-$ & $+/-$ \\
\hline VCG $2 \mathrm{Ba}$ & V702I.M & $+/-$ & + & & \\
\hline VCG $2 A B$ & $530-1.1$ & & & $+/-$ & $+/-$ \\
\hline VCG $2 A B$ & $25 \mathrm{~V} .1$ & & & + & $+/-$ \\
\hline VCG $2 A B$ & 530-1.M & + & + & & \\
\hline VCG $2 A B$ & 25V.M & $+/-$ & $+/-$ & & \\
\hline VCG 2B-2A & CA26.M & $+/-$ & $+/-$ & & \\
\hline VCG 3 & PCW.1 & & & - & $+/-$ \\
\hline VCG 3 & 70-21.M & - & - & & \\
\hline VCG 4A & BB. 1 & & & - & - \\
\hline VCG 4A & Dvd-E6.M & - & - & & \\
\hline VCG 4B & V684I.1 & & & - & - \\
\hline VCG 4B & S39.M & - & - & & \\
\hline VCG 6 & Ca. 148.1 & & & - & - \\
\hline VCG 6 & Ca.146.M & - & - & & \\
\hline $\mathrm{HSI}$ & V13.1 & & & - & - \\
\hline $\mathrm{HSI}$ & Cf.162.M & - & - & & \\
\hline
\end{tabular}

1 The vigour of complementation reactions is indicated by "+" (strong reaction characterised by dense prototrophic mycelial growth and extended microsclerotia production), "+/-" (weak reaction with slight mycelial growth and/or limited microsclerotia production), or "-" (absence of prototrophic growth). Each pairing was performed in triplicate. 